BETTER PREDICTIONS, BETTER ALLOCATIONS: SCIENTIFIC ADVANCES AND ADAPTATION TO CLIMATE CHANGE

\author{
Mark C. Freeman \\ Ben Groom \\ Richard Zeckhauser \\ Working Paper 21463 \\ http://www.nber.org/papers/w21463 \\ NATIONAL BUREAU OF ECONOMIC RESEARCH \\ 1050 Massachusetts Avenue \\ Cambridge, MA 02138 \\ August 2015
}

The views expressed herein are those of the authors and do not necessarily reflect the views of the National Bureau of Economic Research.

NBER working papers are circulated for discussion and comment purposes. They have not been peerreviewed or been subject to the review by the NBER Board of Directors that accompanies official NBER publications.

(C) 2015 by Mark C. Freeman, Ben Groom, and Richard Zeckhauser. All rights reserved. Short sections of text, not to exceed two paragraphs, may be quoted without explicit permission provided that full credit, including $(\mathcal{C}$ notice, is given to the source. 
Better Predictions, Better Allocations: Scientific Advances and Adaptation to Climate Change Mark C. Freeman, Ben Groom, and Richard Zeckhauser

NBER Working Paper No. 21463

August 2015

JEL No. D8,D83,E21,H41,H43,Q5,Q54

\begin{abstract}
The initial hope for climate science was that an improved understanding of what the future might bring would lead to appropriate public policies and effective international climate agreements. Even if that hope is not realized, as now seems likely, scientific advances leading to a more refined assessment of the uncertainties surrounding the future impacts of climate change would facilitate more appropriate adaptation measures. Such measures might involve shifting modes or locales of production, for example. This article focuses on two broader tools: consumption smoothing in anticipation of future losses, and physical adaptation measures to reduce damages. It shows that informative signals on climate-change effects lead to better decisions in the use of each tool.
\end{abstract}

Mark C. Freeman

School of Business and Economics

Loughborough University

Leiceistershire, UK LE11 3TU

m.c.freeman@lboro.ac.uk

Ben Groom

Department of Geography and Environment

London School of Economics

Houghton St, London, WC2A 2AE, UK

b.groom@1se.ac.uk
Richard Zeckhauser

John F. Kennedy School of Government

Harvard University

79 John F. Kennedy Street

Cambridge, MA 02138

and NBER

richard_zeckhauser@harvard.edu 


\title{
Better Predictions, Better Allocations: Scientific Advances and Adaptation to Climate Change
}

\author{
Mark C. Freeman ${ }^{1}$, Ben Groom ${ }^{2}$ and Richard Zeckhauser ${ }^{3}$ *
}

August 14, 2015

\begin{abstract}
The initial hope for climate science was that an improved understanding of what the future might bring would lead to appropriate public policies and effective international climate agreements. Even if that hope is not realized, as now seems likely, scientific advances leading to a more refined assessment of the uncertainties surrounding the future impacts of climate change would facilitate more appropriate adaptation measures. Such measures might involve shifting modes or locales of production, for example. This article focuses on two broader tools: consumption smoothing in anticipation of future losses, and physical adaptation measures to reduce damages. It shows that informative signals on climate-change effects lead to better decisions in the use of each tool.
\end{abstract}

\section{Introduction}

However rewarding life as a climate scientist must be, the absence of binding international agreements on climate change mitigation and the slow pace of climate policy reform must make it frustrating in equal measure. What is the point, one may well ask, of continuing to refine the science of climate change if effective collective action seems so unlikely? The message of this article is that receiving clearer signals about

\footnotetext{
${ }^{* 1}$ School of Business and Economics, Loughborough University. Author for correspondence: m.c.freeman@lboro.ac.uk. ${ }^{2}$ Department of Geography and Environment, London School of Economics. ${ }^{3}$ Kennedy School, Harvard University.
} 
the likelihood of future states of a warmer world would provide substantial utility, even in the absence of binding global agreements, or effective national policies on mitigation. Signals provide the basis upon which the adaptation activities of sovereign nations, regions, firms and even individuals are made. Their utility lies in enabling more informed saving and consumption-smoothing decisions, but informed signals are particularly valuable when physical adaptation measures are also available, such as flood defenses or choice of location. So, although the primary impetus for climate research was to inform and influence high-level negotiations on collective action, knowing more about the likelihood of future outcomes is also a valuable input both for individual governments, and for agents within them at lower, more decentralised organisational levels. These are the parties who will ultimately make adaptation decisions, irrespective of the success of international agreements.

The article focuses on adaptation because it is an inevitable part of the response to climate change [1]. The best predictions so far suggest that, whatever is agreed at the 21st Conference of Parties in Paris in December this year (COP21), there is by now sufficient inertia in the climate system to lock-in temperature increases of between 0.3 and 0.7 degrees Celsius (C) for the period 2016 - 2035 relative to 19862005 [2, 3]. For the period 2080-2100 temperature change is expected to exceed 1.5C for all but the most stringent Representative Concentration Pathways (RCP). These predictions suggest that the focal-point of a $2 \mathrm{C}$ limit enshrined in the Copenhagen Accord is likely to be unrealistic Indeed RCP2.6, the most stringent of the RCPs contained in the Fifth Assessment Report of the IPCC (AR5), shows that in order for the $2 \mathrm{C}$ limit not to be exceeded, emissions of $\mathrm{CO}_{2}$ equivalents will have to turn negative towards the end of the 21st century ${ }^{2}$

Given previous experience, agreement on such stringent emissions reduction scenarios at the COP21 seems distinctly unlikely. It has been argued for some time that the nature of climate change as a spatial and intergenerational problem, together with the absence of an enforcement mechanism within the Kyoto Protocol and successive agreements, more or less precludes agreement on collective action [5, 6, 7, 8]. There are straightforward free-rider problems: non-signatories benefit from the action of signatories thereby reducing the incentive to participate in an international agreement. Many countries also recognise that a successful interna-

\footnotetext{
${ }^{1}$ The Copenhagen Accord arising out of the COP15 states that the parties agreed that in order to avoid dangerous anthropogenic climate change they recognise 'the scientific view that the increase in global temperature should be below 2 degrees Celsius' compared to the pre-industrial average (4], article 1)

${ }^{2}$ Given uncertainty, the phrase 'likely to be met' is used. This has a particular probabilistic meaning in the AR5 report meaning a likelihood of between $66-100 \%$, as do terms like 'virtually certain' (99-100\%), 'highly likely' (90-100\%) and 'very unlikely' (0-10\%).
} 
tional response to climate change mitigation requires the participation of the two major contributors to greenhouse gases (GHGs), China and the US. So far the US has shied away from signing the Kyoto protocol, while China remains a Non-Annex I country without any obligations under the principal of 'shared but differentiated responsibilities' $]^{3}$ Moreover, given that the two countries are in such asymmetric situations, an agreement that looks fair to one will look unfair to the other.

As a counter-argument we might look to the recent Sino-US pledges on emissions reductions $4^{4}$ But even here enforcement is lacking; there are no clear plans of implementation on either side, and the reliance of the US pledge on executive authority means it is liable to be reversed under a Republican administration 5 The asymmetry of these respective pledges reflects the inherent asymmetry of the problem more generally. A global agreement must resolve the fact that negotiating countries are at very different stages of development, and that the Least Developed Countries (LDCs) will either require compensation for stringent emissions reductions, or will only commit to mitigation once development has taken place [10] $]^{6}$ Even if the Sino-US pledge is successful therefore, energy demand is still predicted to increase as incomes in LDCs, not to mention populations, increase in the future [12, 11]. For all of these reasons, adaptation is now an unavoidable feature of the response to climate change, particularly in LDCs. This view is reflected in the high-level institutions of the UN Framework Convention on Climate Change (UNFCCC) with the formation at the COP16 in Cancun of the Cancun Adaptation Framework and associated Adaptation Committee. Similarly, both AR4 and AR5 [3, 2] have detailed chapters devoted entirely to adaptation: $]^{7}$

Of course, just like mitigation, adaptation decisions must be made despite considerable uncertainty about the impact of climate change in the future. As one looks into the distant future, as is necessary for such problems that stretch across gen-

\footnotetext{
${ }^{3}$ It has also been shown theoretically and in behavioural experiments that uncertainty surrounding climate damages tends to make agreement even less likely, particularly with regard to the location of catastrophic thresholds such as the $2 \mathrm{C}$ of the Copenhagen Accord [9].

${ }^{4}$ In November the Obama administration pledged a 26-28\% reduction in GHG emissions by 2025 , while President Xi simultaneously made a general pledge for emissions reduction after 2030. These pledges were submitted to the UNFCCC in March 2015.

${ }^{5}$ See http://www.nytimes.com/2015/04/01/us/obama-to-offer-major-blueprint-on-climatechange.html?

${ }^{6}$ If they were at the same stage of development, with the same history of emissions, equal populations, and equal current emissions, it would be relatively easy for the two countries to agree say on a $\mathrm{K} \%$ cut in emissions.

${ }^{7}$ That climate change can be viewed as a development problem (e.g., 10]) is not a new idea. There is also a long standing argument that the best adaptive response to climate for LDCs would be to grow and reduce vulnerability in the future [13].
} 
erations, every aspect of the problem becomes increasingly fuzzy. It is not simply that the probability distributions attached to events widen and lead to less precise estimates of key variables, we are also uncertain about the probabilities to attach to different outcomes in the deep future. These responses to climate change must be taken in an environment of uncertainty and ambiguity rather than risk 8 The chief sources of uncertainty in our understanding of future climate change are threefold: i) the level of future emissions; ii) the impact of emissions on temperatures; and, iii) the damages that arise [15]. Take for instance 'climate sensitivity', which measures the increase in temperature from a doubling of $\mathrm{CO}_{2}$. Estimates of this parameter in the AR5 come from many and various climate models. The disagreement among them is plain to see in Figure 1. Yet, with the passing of time scientific research will improve our understanding of such relationships. We can expect the uncertainty surrounding these factors to narrow either in the sense of obtaining more precise predictions or obtaining closer agreement among climate models, not to mention experts, on the extent of uncertainty. The same can be said for the difficult practice of estimating climate damages. Ultimately though, the relevant information to improve adaptation decisions would be provided at a local level. Here too we can expect better information to narrow the disagreement among models that currently exists [17]. Adaptation in many sectors can then be placed on a firmer footing as a consequence of better information [12, 17, 16]. This belief is widely held. $9^{9}$

In this paper we ask the question: what is the value of scientific research in providing more informative signals on the future of climate change for agents faced with adaptation decisions? To answer this question we use a parsimonious model of an atomistic agent who could be the government of a sovereign nation, a local government, a firm, or an individual household. The agent has the capability of making two separate decisions about how to optimally respond to climate change in the future: a 'macro' consumption-saving decision that builds up a fund for future adaptive responses and buffers future losses (e.g., repairs to a damaged house, or purchase of grain in the event of crop losses), and a 'micro' physical adaptation decision that limits future climate related damages (although not climate change itself). In one future state of the world, a high temperature state, damages are severe and endowments are low. In another damages are only moderate. The agent

\footnotetext{
${ }^{8}$ With climate change, it is also important to consider the more extreme situation of ignorance, where even some important possible states of the world cannot be identified [14].

${ }^{9}$ For instance, the World Meteorological Organisation states increased acceptance that some degree of climate change is inevitable is now coupled with increasing demand from communities, industry and government for reliable climate information at high resolution and with accurate extremes. Cited in [16].
} 
knows that before she commits to a micro or macro adaptation decision a signal of a particular quality will arrive that updates the information held about the probability of the severe state arising. The signal will either be 'good' or 'bad' in the sense of lowering or raising the probability of the severe state compared to previously held beliefs. With the signal in hand, the agent will then make her optimal micro and macro adaptation decisions.10 We analyse the utility of the better signals by comparing the agent's pre-signal expected utility both with and without the signal. We also look at signals of different qualities.

The value of information has been analysed before in the context of climate change and adaptation. Our work relates to two strands of the preceding literature. In the first, the option value of arriving information has been analysed following a framework long since established [18, 19, 20]. Here the essential problem was that an agent must make a decision today knowing that a better signal will arrive in the future. In this context the agent can wait and see and the problem becomes one of the optimal timing of adaptation given some irreversibility of investments and/or climate damages. In the second strand, the implications for the precision of climate predictions has been analysed for an agent who receives a short-run and a longrun prediction without knowing that the signal may improve in time. The question here concerns the relative value of short-run and long-run predictions [15, 16]. Our approach differs from these in that it evaluates a world in which information is improving via a future signal and yet agents make some decisions ex post. Evaluated ex ante, we capture an essential value of better signals on saving and adaptation decisions, but strip out issues of option value and irreversibility.

The initial result of this article is that under typical assumptions positing risk aversion, the agent would prefer to be in the world with the signal than without. In a world with definitive signals about the future, expected utility increases compared to in the absence of a signal. The pathways for this result are clear. In the macro adaptation case, better information effectively reduces uncertainty in the future and reduces precautionary saving. This effect is monotonic in the conclusiveness of the signal. The value of the signal is even higher when micro adaptation strategies are also available. Signals allow a better tailoring of these adaptations to different states of the world. However, the devil is in the details. Our analysis then examines how properties of the consumption utility function affect levels of savings and physical adaptation. We present both analytic results and numerical calculations. The latter illustrate, for example, the non-monotonic way in which micro and macro adaptations respond as signals improve.

\footnotetext{
${ }^{10}$ See Figure 2 for an illustration the sequence of events. Figure 3 describes the nature of the signal.
} 


\section{Scientific Uncertainty in Climate Change}

In this section we discuss the pervasive uncertainties associated with climate change. This is done with a view to understanding where continued scientific research may be able to provide better signals about the future of climate change. Given the focus of this article, it is worth being clear about the sources of uncertainty discussed in the context of climate change. We begin by categorising what we know about its prospects in the future. Taken together, [21] and [15] provide a helpful structure, which we now summarise.

Predicting the future is a difficult task at the best of times, but the sheer complexity and time horizon associated with climate change amplifies these difficulties. Our knowledge about the future of climate change comes from two main sources: i) scientific principles, including physical laws; and, ii) the empirical predictions of climate models. While the principles are matters of fact, the movement from principles to predictions leads to an uncertain picture of the future as the models attempt to reproduce extremely complex systems using different assumptions and calibrations. Each model is subject to its own errors and potential omissions [22]. The essential sources of uncertainty in predicting climate change are threefold: i) the path of future greenhouse gas (GHG) emissions; ii) the relationship between GHG concentrations and temperature change; and, iii) the link between temperature change and damages [15]. In the context of adaptation, the uncertain process of technological change means that the future costs of adaptation are also a source of uncertainty about the future, just as abatement costs are uncertain when thinking about mitigation. More specifically, with regard to climate change and damages, we are much more uncertain about predictions with longer lead times or greater spatial definition. The distant future, and country or regional level predictions are 'fuzzier' than short-term or global predictions [21].

When thinking about adaptation to climate change, decisions will depend upon the uncertainty surrounding future exposure to climate damages. Exposure to climate change will depend on each of the elements i to iii above. Future emissions paths are undoubtedly difficult to predict, but calibrating the damage function is one of the key weaknesses of Integrated Assessment Models and a source of great uncertainty [23, 24]. At present damage functions are constructed on the basis of 'ad hoc assumptions based on loose extrapolations and intuition' [25]. Small changes in the parameterisation lead to large changes in estimated damages and associated policy recommendations. The AR5 cites only a dozen or so sources for its estimates of the damage function, many of which come from the same experts. It is widely regarded as an area ripe for improvements in understanding and more refined information on 
uncertainty [2].

The relationship between GHG concentrations and temperature change is usually summarised by a parameter known as climate sensitivity [21]. Climate sensitivity measures the long-run temperature change associated with a doubling of $\mathrm{CO}_{2}$ in the atmosphere above pre-industrial levels. Together with predicted emissions paths and damage functions it is one of the key pieces of the climate-change puzzle. In contrast to the damage function, climate sensitivity has received a great deal of scientific research. Despite this, its value remains very uncertain [26, 15]. To illustrate the way in which different models disagree on climate predictions, consider their estimates of climate sensitivity. Figure 1 shows the probability density functions for climate sensitivity for a number of prominent climate models. From this it is clear that models disagree on the likelihoods to attach to different values of climate sensitivity: there is uncertainty rather than simply risk. For decision making purposes, these estimates are typically aggregated into a single density function, either by Bayesian methods as used in AR5 or by using expert assessment. Even then the aggregated climate sensitivity remains a source of great uncertainty. Using such methods the 'likely range' of climate sensitivity, meaning the central $66 \%$ of the distribution of estimates, is currently $1.5-4.5 \mathrm{C}$. This range has remained somewhat steadfast since the First Assessment Report of the IPCC (AR1), with only a brief narrowing of the range at the time of the Fourth Assessment Report in 2007 (AR4) to 2 - 4.5C. ${ }^{11}$ As well as the likely range, the summary distribution of climate sensitivity reported in AR5 provides information about the likelihood of extreme, high temperature states of the world. For instance, the likelihood of a temperature rise in excess of $6 \mathrm{C}$ is approximately $10 \%$ [26]. Some have argued that climate policy ought to be organised around this information rather than the central ranges, since increases in temperature of this magnitude would represent truly catastrophic outcomes, which make up the vast majority of expected losses 28].

Climate sensitivity and climate damages are good examples of the information we can expect from research on climate change. They act as guides to the analysis of climate scenarios and provide the essential information upon which climate negotiations and adaptation decisions are made. There are several areas where improvements in this kind of scientific information are likely. Firstly, the estimates of climate sensitivity used in the AR5 are derived from multiple climate models and also involve expert opinions. With passing time, temperatures and $\mathrm{CO}_{2}$ emissions will move further into uncharted territory, scientists will learn more about the complex climatic relationships. The recent and unpredicted slowdown of global temperature

\footnotetext{
${ }^{11}$ The physical reasons for the robustness of the distribution of climate sensitivity have been well documented [27].
} 
changes, which lead to closer scrutiny of the role of ocean warming, is a good example of this learning process. As a result, climate models will gain in the accuracy in their predictions as we learn more about their underlying physical laws. Their distributions of climate sensitivity will tighten, and disagreement among models will diminish. New models will also arrive. Similar arguments can be made for the damage function and knowledge of how humans will respond to these changes, for example through migrations, wars, etc. In each case we can expect that more refined scientific information will give us better, though still highly uncertain, predictions on average.

Yet learning is also likely in relation to more esoteric issues, such as how to best to aggregate models and expert opinions [22, 29]. For instance, expert opinions provide a useful source of information for estimating climate sensitivity since their subjective probabilities are calculated using their experience with a variety of climate models and their expert views of their advantages and shortcomings. However, experimental evidence indicates that experts do not always satisfy the axioms of rationality that motivate the use of subjective probabilities in the first place [29]. Probabilities derived this way may paint a more optimistic or pessimistic picture of the uncertainties that we face, compared to more appropriate aggregation methods [29, 21]. Even without these behavioural/rationality issues, others argue that simply combining the results from climate models to form a single distribution of climate sensitivity only captures a fraction of the uncertainty that we face, and ignores the deeper uncertainties contained in individual climate models. It could well be that other representations of uncertainty might be more appropriate [22], or alternative decision-making frameworks should be used to account explicitly for the inherent ambiguity of climate sensitivity [21].

Finally, making predictions at higher levels of geographical definition represents another source of profound uncertainty. Country level predictions of the evolution of climate change are notoriously imprecise since they depend on local environmental factors such as topography. This is particularly true for precipitation, since the science of cloud formation is subject to stochastic processes which are less wellunderstood. Consider, for example, the predictions for temperature and precipitation in China for the decades up to 2050 and 2100 coming from three prominent climate models: the Hadley Centre Coupled Model (HCMIII), the Parallel Climate Model (PCM2), and the Community Climate Model (CCM2) [17].12 While each predicts more or less the same temperature rise on average, some predict more precipitation in the future, while others predict significantly less [17]. Improving the accuracy and

\footnotetext{
${ }^{12}$ http://www.cgd.ucar.edu/pcm/ $\quad$ http://www.metoffice.gov.uk/research/modellingsystems/unified-model/climate-models/hadcm3; http://www.cgd.ucar.edu/cms/ccm3/
} 
precision of spatially defined predictions is one area in which additional research will bear fruit [16, 15].

There are several areas where scientific research will be able to either improve predictions or at least provide more informative signals about how much uncertainty we are facing. Some types of uncertainty are more likely to be reduced than others. For instance, the errors and omissions of climate models may well be ironed out with sustained research. In time research may refine the spatially and temporally specific predictions that are needed to inform decentralised adaptation decisions. Some scientists believe that a tripling of current funding levels would reduce uncertainty in transient climate response, an element of climate sensitivity, by approximately $1 / 3$ [15, 30.

Simple practical examples exist of where a clearer picture of the uncertainty facing potential agents has assisted in their adaptation/risk management decisions. In The Netherlands maps have been produced that clarify the probability of flooding in different locales [31. Elsewhere, better predictions of the danger zones for natural disasters have also been provided [32]. There is a growing demand for such information from international organisations, commercial quarters, and local planners alike [16]. The provision of such information is also taken seriously by major global organisations. For example, provision of this kind of information is a major component of the World Meteorological Organisation's Global Framework for Climate Services [15]. Of course, we must remain mindful that uncertainty surrounding some aspects of climate analysis is likely to be irreducible. The processes of cloud formation, the path of future emissions, and many other socio-economic processes, are extremely difficult to narrow down. Such quantities may well dominate uncertainty in the longrun [15, 16]. Yet, more informative signals about the likelihoods of different future states of the world are possible, and are widely seen as crucial for making adaptation decisions in many different circumstances 33 .

Improvement in the information about the future can in principle come from any or all of the three (i to iii) sources of uncertainty discussed above. In our formal analysis the signal concerning the probability of severe (high temperature, high damage) state stems from from better information on climate sensitivity or emissions, rather than damages. Before going into the details, we discuss some specifics of adaptation.

[Insert Figure 1 here] 


\section{Adaptation as a response to climate change}

\subsection{A brief history of adaptation in climate negotiations}

Adaptation has shifted from being virtually a taboo subject in the early years following the UNFCCC to receiving more or less equal status in recent meetings of the Conference of Parties [34]. The fear in the past was that discussion about adaptation would undermine efforts to agree on mitigation targets. Al Gore made this point forcefully when he said that focusing on adaptation represented 'a kind of laziness, an arrogant faith in our ability to react in time to save our skins'. The United Nations Framework Convention on Climate Change (UNFCCC) devoted little time to the issue and took a very narrow view of adaptation as a simple reactive behaviour to future climate change.

Three main factors have led to this change in emphasis. First, inertia in the climate system means that the full effect of historical emissions is yet to be felt. To quote the Stern Review, 'there are some unavoidable impacts of climate change to which the world is already committed' [35]. Second, equity issues have dictated a shift in focus towards the impact on developing countries, which are the most vulnerable to climate change due to their reliance on climate sensitive sectors such as agriculture, forestry and fisheries [36] ${ }^{13}$ Third, quite apart from equity issues, there has been also a strong sense that the focus on mitigation to reduce climate risks in the future ignored the very real prospect of current climate and non-climate related development issues, such as the control of malaria. The objectives of adaptation strategies often overlap with those of development more generally [34].

Precisely these arguments have elevated adaptation to more or less equal status with mitigation in high-level negotiations and associated institutions. The outcome of the COP16 in Cancun, and agreement on the Cancun Adaptation Framework $(\mathrm{CAF})$, is testament to this ${ }^{14}$ The CAF recommended the development of National Adaptation Plans (NAPs) for Lesser Developed Countries (LDCs), as well as work programmes for vulnerable countries, such as Bangladesh, to potentially address loss and damage associated with climate change. Under the CAF, additional support from developed countries comes in the form of provision of, inter alia, the best available scientific evidence on adaptation strategies and climate change itself [38].

\footnotetext{
${ }^{13}$ Whether these expressed concerns reflect deeply held values, which would lead for example to significant transfers of resources to developing countries, or are merely pious utterances that will be followed with significant actions, is unclear.

${ }^{14}$ The Delhi Declaration of 2002 which called for a greater focus on the plight of developing countries in international negotiations, leading to the Bali Action Plan of 2007, and arguments in academia have all assisted in the integration of adaptation into the UNFCCC [34, 37].
} 
National and local level assistance on adaptation is to be coordinated and provided by the Adaptation Committee of the CAF.

The salient aspects of the Cancun Agreement, the CAF and the Adaptation Committee for the purposes of this article concern their role in the provision of information and the promotion of scientific research on climate change. For instance, the Cancun Agreement ${ }^{15}$ states that one of the key roles of the CAF is: 'Strengthening data, information and knowledge systems; and, improving climate-related research and systematic observation for climate data collection .... in order to provide decision makers at the national and regional levels with improved climate-related data and information'. Furthermore, the Adaptation Committee's objectives include: 'Sharing of relevant information, knowledge, experience and good practices; and, providing information and recommendations, drawing on adaptation good practices, for consideration by the COP when providing guidance .... on adaptation actions'. ${ }^{16}$ In short, adaptation is now taken very seriously by high-level climate institutions, and the provision of scientific information to potential adapters is now an important part of the adaptation framework.

\subsection{Categories of adaptation}

This article evaluates the benefits of information provision to those those who make adaptive decisions at whatever level of organisation: national, regional, community or individual. This is an issue of growing importance in international negotiations on climate change. Adaptation can take various forms and has various definitions which are worth articulating for the purpose of understanding our formal model.

One important distinction in the literature on adaptation (e.g., [39]) focuses on the temporal dimension of decision making and draws the distinction between reactive and anticipatory adaptation. Reactive activities are rolling contemporaneous responses to events caused by climate change. For instance, buying sandbags in response to a flood to prevent damage to one's house [31]. Anticipatory or 'pro-active' adaptation [40] takes place before the impact of climate change. The construc-

\footnotetext{
${ }^{15}$ Article I, Section $14(\mathrm{~h})$ and (i)

${ }^{16}$ A complete list of objectives is: 1 . Providing technical support and guidance to the Parties; 2. Sharing of relevant information, knowledge, experience and good practices; 3. Promoting synergy and strengthening engagement with national, regional and international organizations, centres and networks; 4. Providing information and recommendations, drawing on adaptation good practices, for consideration by the $\mathrm{COP}$ when providing guidance on means to incentivize the implementation of adaptation actions, including finance, technology and capacity-building; 5. Considering information communicated by Parties on their monitoring and review of adaptation actions, support provided and received. For more details see.
} 
tion of sea defenses, changing the design and/or use of houses to limit damage, are good examples of anticipatory adaptations. Another important distinction is made at the organisational/logistical level between planned and autonomous adaptation. Planned adaptation is typically thought to be the realm of government, since it refers largely to public goods and infrastructure which either require coordination or are subject to economies of scale [40. Again, flood defenses in The Netherlands, migration policies in Bangladesh or public health responses in the tropics are good examples. Autonomous adaptation is more decentralised to the local or individual level. In agriculture, it may take the form of crop switching, input switching or irrigation [41, 42]. In industry, air-conditioning in factories represents one possible adaptation to higher temperatures [43. Rural-urban migration and urbanisation in general are other potential adaptations which may to ameliorate productivity losses [44, 12]. Adaptation can also be organised at the regional or international level, where cooperation over shared river basins is required for instance. With these two distinctions (reactive/anticipatory and planned/autonomous) there are clearly 4 possible categories of adaptation. 17 .

Adaptation decisions clearly differ in the way in which they ameliorate the impact of climate change. Some defensive investments, such as wetland flood defenses, reduce the losses associated with any given flood by reducing the amount of floodwater that arrives at the doorstep. Other defensive adaptations limit the damages associated with floods which do arrive at the doorstep. For instance, changes to the design of housing in flood prone areas such as raising them on stilts, or changing the uses of flood prone basements and lower floors. Such activities are witnessed in flood-prone areas of The Netherlands and the Indus river delta in Pakistan, for instance [45]. Relocating further inland or to higher ground today might be another obvious cost that could be incurred to avoid future climate damages. Alternatively, agents may simply make saving decisions to ameliorate the disaster when it arrives by smoothing consumption. Each strategy represents a type of protection ${ }^{18}$ In agriculture, the equivalent distinction could be drawn between investing in new, say drought resistant crop varieties to stop the damage associated with a given drought, versus storing food or saving money to ameliorate the loss of production from traditional varieties.

Thus a variety of potential adaptation decisions can be made at different levels

\footnotetext{
${ }^{17}$ There are other distinctions in the literature, such as substitute and complementary adaptations 39

${ }^{18} \mathrm{We}$ are careful not to confuse: (i) self-insurance where one avoids marketed insurance and bears the financial and other consequences oneself; (ii) self-protection which reduces the probability of bad outcomes; and, (iii) a non-insurance investment to reduce damages that we call physical adaptation.
} 
of organisation and at different geographical scales. In our formal analysis we allow for the possibility that physical adaptation measures are constrained and households must rely on their consumption-saving decisions to adapt to future climate change. This type of policy can be thought of as a 'macro' adaptation due to the generality of saving and consumption-smoothing as an aggregate strategy. Physical adaptation measures can be thought of as 'micro' adaptations, since they act at the level of the individual agent. In any given case, an optimal response would weigh the benefits of each strategy based on the institutional and technological constraints at hand [1].

The principal of subsidiarity is probably the relevant principle to determine the appropriate level of decentralisation for any given adaptation decision, and we largely abstract from this discussion here [40]. As we discuss in the following section, our primary interest is in anticipatory adaptation, either by saving or investing in physical adaptation. These anticipatory decisions will allow the agent either to respond to climate outcomes in the future or limit the damages. Each decision uses the available information on the likely progression of climate change and the states of the world that may arise in the future. Our interest is to find out the value of more informative signals on climate change in informing these adaptation decisions. We now describe the framework of analysis in more detail.

\section{The Framework}

In this section we describe the framework with which we value the arrival of an informative signal on future climate change for a decision maker deciding on how to adapt to future states of the world. We use a stripped down 2-period model, which reduces the problem to the essential features we wish to explore. The model reflects the aforementioned aspects of adaptation decisions in that the agent may adapt by either saving money or investing in damage reduction. The agent we consider can just as well be thought of as a sovereign nation planning adaptation unilaterally: e.g. Bangladesh, The Netherlands, the UK, an individual household making adaptation decisions: crop choice; flood defenses; saving, or anything in between. The model embodies the principle of subsidiarity in that agent can be thought of as being at the appropriate organisational level for the decision at hand and knows best how much adaptation is desirable. Decisions are made against a backdrop of exogenous mitigation policies and available information about the damage that climate change will cause. Before introducing the theoretical model, the following section outlines some measurement issues associated with valuing the arrival of informative signals in the context of adaptation.

[insert Figures 2 and 3 here] 


\subsection{The impact of the impact of adaptation: measurement issues}

Our analysis considers adaptation measures at an aggregated level. Thus, for example, we do not assess whether a house is built on stilts, a wetland is restored, a factory is put in a less convenient but better protected position or a less valuable but more drought-resistant crop is planted. The first part of our model focuses merely on raising or lowering period 1 consumption as the signal on the period 2 climate effects, i.e., the level of the future endowment, arrives. Subsequently, in our numerical calculations, we consider period 1 physical adaptation expenditures.

Most economic analyses of climate change focus on GDP, and treat it almost equivalently to welfare. Though our analysis is fundamentally economic, and pays primary attention to consumption levels, it differs from these treatments in several ways. First, it recognizes that climate change may bring about effects quite apart from GDP that affect welfare. For example, a higher sea level might destroy beaches where humans had liked to recreate. Higher temperatures may affect health via pollution effects or disease vectors. It would not be surprising that if climate change is severe, a sizeable portion of the welfare losses, whether GDP-related or not, would result from human actions in response to climate change that adversely affected other humans. For example, if climate change creates significant migrations, which in turn create debilitating ethnic tensions, wars or political disruptions, humans would be much worse off, even if GDP were not influenced. Such non-GDP effects are implicitly included in the loss of endowments in future periods.

Second, GDP, as currently measured, does not consider capital destroyed or rendered less valuable. Regions that experience natural disasters often experience rises in measured GDP, given the reconstruction activity that follows. That would be true even if all the reconstruction dollars came from the affected communities. However, that is just a mis-measurement problem. Our focus is on consumption as commonly understood, goods and services available to provide consumptive pleasures. The adaptation measures explicitly considered here all take place in the first period. Of course, whether climate change is moderate or severe, there will also be responsive adaptation in the second period, such as moving production facilities or building a sea wall. The reader should think of the cost of those measures being added to any losses in second-period consumption as being part of the reduction of the secondperiod endowment.

Thus, the basic framework we are considering chooses consumption and (subsequently) physical adaptation expenditures in period 1 taking into account what is known about the the period 2 endowment. Its primary goal is to determine how im- 
proved knowledge of that endowment affects welfare and first-period expenditures. There is one class of measures that could be undertaken to cope with climate change that is not explicitly part of this analysis, geo-engineering and research into geoengineering. Geo-engineering could be thought of either as adaptation or mitigation. The former interpretation looks at its potential to decrease the losses from climate change; the latter sees that, if successful, it actually reduces climate change. Readers who wish to, however, could interpret first-period undertakings related to geo-engineering as being self insurance expenditures ${ }^{19}$

\subsection{The Theoretical Model}

We consider an agent at time $1-\delta$ who is anticipating decisions that he or she might make one instant later at $t=1$, the outset of period 1 . The level of income for period $1, e_{1}$, is known now, but the decision the agent must make is how much of this endowment to consume immediately, $c_{1}$, and how much instead to save in a zero-interest rate bank account ${ }^{20}$ The agent knows that in the second, and final, period, the level of climate change will be either moderate or severe and assigns unconditional probabilities of $p$ and $1-p$ respectively to those two states occurring. Income for period $2, e_{2}$, will be high, $h$, if climate change is moderate, or low, $l$, if it is severe. To reiterate, income in period 2 is what is available for consumption. Thus, it is net of adaptation expenditures made that period.

We consider the value of scientific knowledge that arrives in the interval $t \in$ $[1-\delta, 1]$, what we treat as a signal, that helps the agent refine the probabilities of the moderate and severe states. A signal can be good or bad. A good signal increases the probability that the agent assigns to climate change being moderate to $p+\varepsilon_{G}$ for $0 \leq \varepsilon_{G} \leq 1-p$, whereas a bad signal reduces that probability to $p-\varepsilon_{B}$ for $0 \leq \varepsilon_{B} \leq p$. The realisation of climate change at time 2 is consistent with these revised probabilities. In the case when $\varepsilon_{G}=\varepsilon_{B}=0$, the signal is completely uninformative. When $\varepsilon_{G}=1-p$ and $\varepsilon_{B}=p$, then the signal is fully informative and all uncertainty is resolved at $t=1$ rather than $t=2$. Other permissible values of $\varepsilon_{G}$ and $\varepsilon_{B}$ that do not lead respectively to a sum of 1 or 0 represent partial signals.

At time $1-\delta$, the agent does not know whether the signal will be good or bad. However, he is anticipating scientific advances that will result with probability $\pi$ in

\footnotetext{
${ }^{19}$ Geo-engineering as a response to climate change has been discussed at length in a special issue of the Philosophical Transactions of the Royal Society A [46]

${ }^{20}$ The model could readily accommodate a non-zero interest rate. However, the notation would become more complex whereas understanding would not be enhanced. In the numerical section below, we also introduce a second investment option at $t=1$, which is a physical adaptation measure that gives partial economic protection in the severe state.
} 
the good signal arriving and $(1-\pi)$ in the bad signal arriving. The parameter values $\pi, \varepsilon_{G}$, and $\varepsilon_{B}$ are all known at $t=1-\delta$. For consistency with the unconditional probabilities, these three variables are constrained through the relationship $\varepsilon_{B}=$ $\pi \varepsilon_{G} /(1-\pi)$ for any $p$.

Since the bank interest rate is zero, the agent faces the budget constraint that $c_{1}+c_{2}=e_{1}+e_{2}$, where $c_{2}$ is period 2's consumption level. Except in the case of a full signal, $e_{2}$ remains unknown at $t=1$; thus uncertainty over period 2 consumption will remain when the savings decision is made. $c_{1}$ is chosen to maximise the agent's expected total welfare over the two periods. It is assumed that this welfare can be expressed in terms of a time-separable utility function in the single consumption good, $U(c)$, where the rate of pure time preference is equal to zero ${ }^{21}$ The agent's optimisation problem can then be expressed as:

$$
\Psi=\max _{c_{1}} E_{1}\left[U\left(c_{1}\right)+U\left(c_{2}\right)\right] \quad \text { subject to } c_{1}+c_{2}=e_{1}+e_{2} .
$$

It is assumed that the utility function is monotonic increasing and concave $\left(U^{\prime}>0, U^{\prime \prime}<0\right)$. These assumptions capture the characteristics that more consumption is preferred to less and that the Pratt-Arrow measure of absolute risk aversion, $A=-U^{\prime \prime} / U^{\prime}$, is positive. We also impose the restriction that the [47] measure of absolute prudence, $P=-U^{\prime \prime \prime} / U^{\prime \prime} \geq 0$, or equivalently, that the third derivative of the utility function is non-negative. This condition is intimately connected to risk aversion. It is easily verified that $P=A-A^{\prime} / A$, so a sufficient (but not necessary) condition for non-negative prudence is the agent's coefficient of absolute risk aversion is not increasing in consumption. As discussed below, prudence, an empirically plausible assumption, plays an important role in this model.

The primary variable of interest is $E_{1-\delta}[\Psi]$, the future welfare that the agent currently expects to enjoy. Specifically, in what ways does scientific advances in the interval $t \in[1-\delta, 1]$ increase $E_{1-\delta}[\Psi]$ despite the fact that the signal neither enables the agent to reduce greenhouse gas emissions nor directly protect himself from the economic consequences of climate change? A second variable of interest is $E_{1-\delta}\left[c_{1}\right]$. Under what circumstances will a signal lead to an increase in the expected consumption level the next instant?

To begin, we compare the case of a full signal $\left(\epsilon_{G}=1-p, \epsilon_{B}=p\right)$ to that of no signal, $\left(\epsilon_{G}=\epsilon_{B}=0\right)$. [22 In this case:

Result 1. If we receive a full signal in the interval $[1-\delta, 1]$, then compared to the case of receiving no signal:

\footnotetext{
${ }^{21}$ Again, it would be straightforward to extend the model for non-zero rates of time preference.

${ }^{22}$ We relax these assumptions in Result 2 below and our numerical illustrations.
} 
1.1 Expected welfare, $E_{1-\delta}[\Psi]$, increases.

1.2 Expected time $t=1$ consumption, $E_{1-\delta}\left[c_{1}\right]$, increases (stays the same) if prudence is positive (prudence is zero).

A formal proof of the result is presented in the Appendix, but the intuition behind it is straightforward. If all uncertainty is removed at time 1 then we can perfectly smooth consumption between times 1 and 2. $c_{1}=c_{2}=\left(e_{1}+h\right) / 2$ if the signal is good or $c_{1}=c_{2}=\left(e_{1}+l\right) / 2$ if the signal is bad. Smooth consumption is always optimal in this economy because $U^{\prime \prime}<0$. Therefore a perfect signal allows us to make the best possible consumption decision at $t=1$ and expected welfare increases.

Result 1.2 follows from the precautionary savings motive described originally by [48]. If an agent is prudent, then future endowment uncertainty will make him save more today against possible future bad outcomes. A full signal completely eradicates uncertainty and therefore the precautionary savings demand is eliminated, raising the expected consumption level at $t=1$.

Result 1.1 verifies the importance of scientific advances even when such enhanced knowledge does not lead to better (or even different) policies, hence not to any alteration in either temperature change or future economic damages. In the appendix we prove that this result applies also to partial signals for any value of $p$. We define a signal as getting stronger if $\varepsilon_{G}$ increases. ${ }^{23}$

Result 2. As the strength of any signal that we receive in the interval $[1-\delta, 1]$ gets stronger:

2.1 Expected welfare, $E_{1-\delta}[\Psi]$, increases.

2.2 Expected time $t=1$ consumption, $E_{1-\delta}\left[c_{1}\right]$, increases (stays the same) if prudence is positive (prudence is zero).

This demonstrates that any scientific advances increases expected welfare as it allows the agent to make a better consumption-savings choice in period 1 . This holds even when there are no projects available to help mitigate the impact of climate change. This is our central qualitative lesson.

\footnotetext{
${ }^{23} \varepsilon_{B}$ also increases as the signal gets stronger as $\varepsilon_{B}=\pi \varepsilon_{G} /(1-\pi)$.
} 


\section{Numerical examples}

We now consider the quantitative magnitude of the effects described in the previous section. For our numerical examples, we define the moderate state to be the least damaging $70 \%$ of possible outcomes and the severe state to include the most damaging $30 \%$ of outcomes. We are currently at year -5 and will, in five years' time $(t=1)$, through the advances of science, receive with equal probability $(\pi=0.5)$ a good or a bad signal about future climate change. This will then enable us to update our probability of the moderate state occurring to $70 \%+\varepsilon$ or $70 \%-\varepsilon$ depending on which signal we receive for $\varepsilon \in[0,0.3] . \varepsilon=0$ represents an entirely uninformative signal. When $\varepsilon=0.3$, a good signal is fully informative but a bad signal is not. There is no material greenhouse gas effect over this initial five year period. Then, $t_{1}$ years after the initial signal, the true state of the world is perfectly revealed and, for $t_{2}=300-t_{1}$ years, we evaluate the economic damages. For the baseline calibration we set $t_{1}=50$ years but, in sensitivity analysis, also consider $t_{1}=100$ years.

Equilibrium climate sensitivity (ECS) will take the value of $S_{m}$ or $S_{s}$ depending on whether the state of the world is ultimately moderate $(m)$ or severe $(s)$. We define $T_{m, t}=2 S_{m}\left(1-0.5^{t / 100}\right)$, which loosely follows [49], to describe the evolution of temperature should the state be moderate. This implies that, at $t=100$, temperature changes equal the ECS and as $t \rightarrow \infty$ so $T_{m, t} \longrightarrow 2 S_{m}$. We define the variable $T_{s, t}=2 S_{s}\left(1-0.5^{t / 100}\right)$ analogously for the severe state.

It is assumed that over the first time interval, $t \in\left[1, t_{1}\right]$, the agent is currently certain that the temperature will follow $T_{m, t}$. During the second period, which ends three hundred years after the signal is received, the temperature also follows $T_{m, t}$ if the state is moderate. However, if the state is severe, then temperatures move smoothly away from the $T_{m, t}$ path towards the $T_{s, t}$ trajectory as $t \rightarrow 300$. Specifically, if the state is severe, then for $t \in\left[t_{1}+1,300\right], T_{t}=w_{t} T_{m, t}+\left(1-w_{t}\right) T_{s, t}$ for a weighting function $w_{t}$ defined by:

$$
w_{t}=\frac{1}{1+\exp (\tau)}, \quad \tau=0.04\left(t-\left(t_{1}+300\right) / 2\right) .
$$

This is an inverted $S$-shaped sigmoid function that gives a smooth transition over the period $\left[t_{1}+1,300\right]$. Notice that when $t=t_{1}+t_{2} / 2$, or half way through the second period, the temperature is half way between $T_{m, t}$ and $T_{s, t}$.

The values of $S$ are calibrated as follows. [49] describes the probability density function for the ECS by a displaced gamma distribution, $\Gamma(\alpha, \theta, c)$ with shape parameter $\alpha=3.8$, scale parameter $\theta=0.92$ and location parameter $c=-1.13$. This gives a mean, standard deviation and skewness for the ECS of 3 degrees, 2.11 degrees and 9.76 respectively. We take the "moderate" outcome to represent values 
of the ECS that are less than 3.8 degrees. This is the value at which the cumulative distribution function for $\Gamma(\alpha, \theta, c)$ is $70 \%$. The severe outcomes represent values of ECS over 3.80 degrees.

To choose $S_{m}$ and $S_{s}$, we take the mean of the truncated displaced gamma distribution $\Gamma(\alpha, \theta, c, u, l)$ where $u$ and $l$ are the upper and lower points of the truncation of the distribution. For the moderate state, $u=3.80$ and $l=c$, while for the severe state, $u=\infty$ and $l=3.80{ }^{24}$ This gives values of $S_{m}=1.89$ degrees and $S_{s}=5.59$ degrees. At $t=300$, these correspond to temperature rises of 3.31 degrees and 9.74 degrees respectively if $t_{1}=50$ years, both well exceeding the 2 degree limit. We plot the evolution of temperature for the severe and moderate states in the top graph of Figure 4.

\section{[Insert Figure 4 around here]}

The change in temperature over time is converted into damages as follows. Let $e_{0}=1$ describe the level of income today. In the absence of climate change damage, $e_{t}^{*}=(1+g)^{t} e_{0}$ for some fixed underlying growth rate $g$. To keep the model as parsimonious as possible, we set $g=0$, but again the analysis could be easily adapted to consider non-zero core growth rates. In the presence of climate change, endowment is affected by a loss function $L\left(T_{t}\right)$ which depends on the level of temperature change at that given time. We take a multiplicative loss form, $e_{t}=L\left(T_{t}\right) e_{t}^{*}$ where the loss function is given by a negative quadratic exponential form used by [51] and [49, 52]:

$$
L\left(T_{t}\right)=\exp \left(-\beta\left(T^{2}\right)\right)
$$

for some constant $\beta$. We set this parameter value equal to $\beta=0.003206$. This represents a $5 \%$ loss in income should the temperature rise by 4 degrees centigrade. [49] notes that this is consistent with the IPCC upper $83 \%$ estimate of potential damages for this level of temperature change. The bottom graph in Figure 4 plots income levels under the moderate and severe scenarios over the interval $t \in[0,300]$ when $t_{1}=50$ years ${ }^{25}$

Total endowment in the first period, $E_{1}=\sum_{t=1}^{t_{1}} e_{t}$ and in the second period $E_{2}=$ $\sum_{t=t_{1}+1}^{300} e_{t}$. When $t_{1}=50$ years, average annual income in the first period is very close to current levels $\left(E_{1} / t_{1}=0.9985\right)$. For the second period, average annual

\footnotetext{
${ }^{24}$ Closed form expressions for the means of truncated univariate distributions are given in [50].

${ }^{25} \mathrm{We}$ actually believe that this estimate may be far too low because it fails to take into account the expectation in loss of GDP, correctly measured, that human actions, such as war and ethnic strife might bring to the world.
} 
income is not heavily affected in the moderate state $\left(E_{2} / t_{2}=0.9787\right)$ but in the severe state drops by just over $11 \%\left(E_{2} / t_{2}=0.8885\right)$ compared to the current level. In sensitivity analysis below we also consider the case when $E_{2} / t_{2}=0.8$.

Since there are no within-period changes in information and as the rate of pure time preference is zero, this implies that the optimal consumption level remains constant within time periods, but will change from period 1 to period 2 . We denote the annual consumption levels by $c_{1}$ and $c_{2}$, and note that the budget constraint is $t_{1} c_{1}+t_{2} c_{2}=E_{1}+E_{2}$. The optimisation problem facing the agent is directly analogous to that described in the theoretical section above. In period 1, endowment can either be saved in a risk-free zero-interest rate bank account or consumed. The savings decision will be influenced by the signal received. Second period consumption is determined by the realisation of $S$ and the savings decision taken in period 1 . If we save $\$ b$ in the bank each year in period 1 , then period 2 consumption is raised by $\$ b t_{1} / t_{2}$ in each year.

We consider five utility functions. Three have constant relative risk aversion (CRRA), which we call "Gamma $=0.5 "$ ", "Gamma $=3$ " and "Log" respectively:

$$
U\left(c_{t}\right)=\left\{\begin{array}{ll}
\frac{c_{t}^{1-\gamma}-1}{1-\gamma} & \gamma \in\{0.5,3\} \\
\ln \left(c_{t}\right) & \gamma=1
\end{array} .\right.
$$

The remaining two functions have constant absolute risk aversion (CARA or "Exponential"), $U\left(c_{t}\right)=-\exp \left(-c_{t}\right)$, and zero prudence ("Quadratic"), $U\left(c_{t}\right)=2 c_{t}-$ $0.5 c_{t}^{2}$. Both the exponential and quadratic utility functions have the same level of risk aversion as log utility at the current level of endowment $c_{t}=e_{0}=1$. In addition, the quadratic utility function has the same marginal utility as log utility at this level of consumption. This makes the utility functions broadly comparable in the analysis.

To determine the optimal level of consumption in the first time period, we use a numerical solver. We report results for $E_{1-\delta}\left[c_{1}\right]=0.5\left(c_{1 G}^{*}+c_{1 B}^{*}\right)$ and $E_{1-\delta}[\Psi]$ $=0.5\left(\Psi_{G}+\Psi_{B}\right)$ where $c_{1 G}^{*}$ and $c_{1 B}^{*}$ represent optimal annual period 1 consumption levels contingent on receiving a good and bad signal respectively. $\Psi_{G}$ and $\Psi_{B}$ represent expected welfare contingent on these respective signals. We report $E_{1-\delta}[\Psi]$ in certainty equivalent consumption form, $c_{C E}$. This variable is defined by $300 U\left(c_{C E}\right)$ $=0.5\left(\Psi_{G}+\Psi_{B}\right)$. The benefit of a signal, $\varepsilon$, is then expressed in terms of the relative change in certainty equivalent consumption with a signal compared to the case of no signal: $c_{C E}(\varepsilon) / c_{C E}(\varepsilon=0)-1$.

Figure 5 reports results for $E_{1-\delta}\left[c_{1}\right]$ and $c_{C E}(\varepsilon) / c_{C E}(\varepsilon=0)-1$ as the strength of the signal changes when $t_{1}=50$ years. These results are consistent with the 
theoretical results described above. In all cases expected welfare is improved by a stronger signal as it allows us better to smooth consumption between periods. The expected level of period 1 consumption also uniformly increases with the strength of the signal for all utility functions except the quadratic, for which $E_{1-\delta}\left[c_{1}\right]$ is invariant for any level of signal. That is because this utility function has zero prudence.

\section{[Insert Figure 5 around here]}

The effects are of considerable economic significance at the global level. Based on world GDP of $\$ 87.25 \mathrm{tn}$ in 2013 (CIA World Factbook 2015), a full good signal $(\varepsilon=0.3)$ compared to no signal increases global welfare, in certainty equivalent consumption terms, by between $\$ 2.5 \mathrm{bn}(\gamma=0.5)$ and $\$ 16.7 \mathrm{bn}(\gamma=3)$ per year for the next 300 years. Let us stress again that this comes not from either changing future temperature levels, or by reducing our economic exposure to climate change, but instead just by learning something earlier about the true level of the ECS which enables us to make better consumption and savings decisions.

Taking log utility as an example, with no signal, each year we consume $95.8 \%$ of our time 0 endowment level, $e_{0}=1$, during this period, saving $4.1 \%$ annually in a bank for the second period. With a full signal, annual savings go down to $1.65 \%$ of time zero income if the signal is good, while rising to $6.33 \%$ if the signal is bad. It is clear that early information has a material affect on behaviour and, overall, increases the expectation that we calculate today of future wellbeing.

\subsection{Physical adaptation measures against the severe state}

In the theoretical section and the first set of numerical examples, the only mechanism by which agents are able to smooth consumption between the first and second periods is through savings at a zero risk-free rate. In this subsection, we introduce a second option for moving resources to the second period. The agent can now choose, in addition to savings, to allocate money over the first $t_{1}$ years into a real investment project that partially protects against the severe outcome, but that has no effect should the state turn out to be moderate. We might imagine this as, for example, the Dutch enhancing their sea defences to protect against the possibility of 'very high sea level rises', or in any nation, factories being placed in less convenient but more secure locations ${ }^{26}$ This project does not alter the evolution of $T_{t}$, but instead partially mitigates against the economic impact of severe climate change.

\footnotetext{
${ }^{26}$ For a discussion of how technology can lead to more flexible adaptation to environmental change without overly exploiting natural systems, see [53]
} 
Let $E_{2}=h, l$ represent the total income levels over years $t \in\left[t_{1}+1,300\right]$ in the absence of any physical adaptation if $S=S_{m}, S_{s}$ respectively. On the calibrations given above, $h=244.69$ and $l=222.13$. Denote by $y \geq 0$ the annual investment in the mitigation project over the first $t_{1}$ years. Then total endowment over the second period is unchanged if the state is moderate, but equals $l^{*}$ if the state is severe, where:

$$
\begin{aligned}
l^{*} & =h-(h-l) \exp (20 y \ln (0.5)) \\
& =h-(h-l) 0.5^{20 y}
\end{aligned}
$$

$l^{*}=l$ as required if $y=0$ and $l^{*}=h$ if $y=\infty$. Infinite investment - obviously impossible since period 1 has only a finite endowment - in this physical adaptation measure will make the economic impacts of moderate and severe temperature changes the same. If we invest $5 \%$ of current income in the project for the next $t_{1}$ years $(y=0.05)$, then we halve the economic differential between the severe and moderate outcomes compared to the case when $y=0$. The residual $b=e_{1}-c_{1}-y$ is saved in the bank at a zero interest rate 27

We again use a numerical solver to choose $c_{1}$ and $y$ so as to optimise welfare at $t=1$ dependent on the signal that we receive. We impose the restriction that $c_{1}+y \leq e_{1}$, which prohibits the agent from borrowing resources against the future. In Figure 6 we report $E_{1-\delta}[y]$ and $E_{1-\delta}[b]$; the amount we expect to invest in physical adaptation and save in the bank respectively.

\section{[Insert Figure 6 around here]}

Both these variables are non-montonic as the signal strengthens. For all utility functions, with $\varepsilon=0$, it is optimal to invest approximately $5 \%$ of time 1 endowment in the physical adaptation measure, with nothing saved in the bank. As the strength of the signal increases, so physical adaptation declines or increases depending on whether the signal is good or bad. Initially the decline with a good signal is greater than the increase with a bad signal, so the expected level of mitigation investment decreases. However, once the signal reaches a certain strength (approximately $\varepsilon=$ $0.15)$ the level of physical adaptation following a good signal falls to zero. Beyond this point, $E_{1-\delta}[y]$ increases along with the signal strength, driven entirely by higher levels of mitigative investment following a bad signal.

\footnotetext{
${ }^{27}$ In sensitivity analysis below, we consider the case when $t_{1}=100$ years. We then change equation 1 so that we need to invest $2 \%$ of income per year over this horizon to halve the impact of severe climate change compared to the moderate outcome.
} 
The expected level of bank savings is zero with no signal; we are better investing in the physical adaptation measure. Further, we never use the bank if the signal is bad. However, when the signal is good and once investment in mitigation approaches zero, then we start to put savings away. For certain moderate signals money is both saved in the bank and invested in the physical adaptation measure, but then the riskfree savings absorb everything invested on behalf of period 2. This savings level then drops as the signal gets stronger still, as there is less need to smooth consumption between the two time periods. In all cases, investment in the physical adaptation measure is expected to be higher than the level of bank savings as it is, in general, a much more effective way of promoting welfare ${ }^{28}$

Figure 7 is analogous to Figure 5, addressing the case when there is the potential to undertake physical adaptation.

\section{[Insert Figure 7 around here]}

Consumption now takes a more complex, non-linear, form compared to when there is no opportunity to invest in physical adaptation. Even when prudence is zero (quadratic utility) expected consumption varies with the strength of the signal. In all cases, $E_{1-\delta}\left(c_{1}\right)$ initially increases as the signal strengthens, but then it declines once $\varepsilon$ is greater than approximately 0.05 . This result is again driven by behaviour following a bad signal, when the desire to move endowment away from consumption and into the self insurance mechanism gets very strong for greater $\varepsilon$.

As intuition would suggest, expected welfare remains monotonic increasing in the strength of the signal. The effect is an order of magnitude greater in the presence of a physical adaptation measure compared to when there is no project that partly mitigates against the economic consequences of severe temperature change. Now the expected annual gain at the global level in consumption equivalent terms when going from no signal to a full good signal is approximately $\$ 500 \mathrm{bn}$ in all cases. The value of early information increases substantially if we can directly protect ourselves against severe outcomes.

\section{$5.2 \quad$ Heterogeneous outcomes}

We now incorporate the possibility that not everyone will be equally affected by a severe outcome. If the state of the world is moderate, then the total endowment over the period $t \in\left[t_{1}+1,300\right]$ is $E_{2}=h$ with certainty. However, if climate change is severe then, with $5 \%$ probability, $E_{2}=0.7 l$. This reflects the fact that some

\footnotetext{
${ }^{28}$ This result, of course, comes from the posited values in equation 5.1
} 
members of the population are likely to be much more severely affected by extreme climate change than others and we are currently unable to determine whether or not we are in the high-risk group. Alternatively, we might posit that individuals are saving or self insuring for the next generation, and care about all its members equally. For the $95 \%$ of the population who are not affected, $E_{2}=1.0158 l$. This keeps the economy-wide average income level in the severe state the same as in the homogeneous agent example. $l^{*}$ follows equation 1 for both the $95 \%$ and $5 \%$ groups. Thus, a $5 \%$ endowment spend over the next $t_{1}=50$ years will halve the difference in income between the moderate and severe states when compared to the no insurance case.

Both in the presence and absence of a mitigative project, the broad shapes of expected consumption, welfare and savings follow the patterns described in Figures 5-7. When physical adaptation is not possible, $t=1$ expected consumption will increase for all four of the positive prudence utility functions as the signal gets stronger. For all five utility functions, expected welfare increases in signal strength. Further, the relative benefit of the full good signal when compared to no signal also now rises for all four of the positive prudence utility functions when compared to the heterogeneous agent model. For example, for $\gamma=3$, the annual certainty equivalent consumption level globally rises from $\$ 16.7 \mathrm{bn}$ for the homogeneous agent model to $\$ 23.4$ bn when there are unequal outcomes.

In the presence of a physical adaptation measure, expected consumption at $t=1$ decreases slightly compared to the homogeneous agent model in all cases. The reduced consumption is primarily transferred into the mitigative project. We invest more in physical adaptation with stronger good signals than in the homogeneous agent case, resulting in the turning points in expected insurance investment and expected consumption being slightly further to the right than in the top graphs of Figures 6 and 7 .

With the potential to self insure and heterogenous agents, the annual certainty equivalent benefit from a full good signal is now over half a billion dollars for all utility functions considered. This is clearly a major societal gain, and it comes even though there is no reduction in future climate change itself.

In Table 1 we summarise the gains in welfare, $c_{C E}(\varepsilon) / c_{C E}(\varepsilon=0)-1$, for sixteen models when receiving the full good signal versus no signal. These unit combinations of four different frameworks: (i) $t_{1}=50$ years and $t_{1}=100$ years; (ii) $l$ calibrated as described above and $l=0.8 t_{2}$, or income is $80 \%$ per year of current endowment in the second period if the state is severe; (iii) homogenous and heterogeneous agent models, and; (iv) bank savings only and bank savings plus the potential to employ the physical adaptation measure. 


\section{[Insert Table 1 around here]}

In all cases, the signal improves welfare, as expected. For our particular parameter values, though not in general, greater gains came from the shorter first period

$\left(t_{1}=50\right.$ years $)$. In general, welfare is improved more when physical adaptation measures are available, income levels are low in the severe state, and agents have heterogeneous incomes.

\section{Conclusion}

Climate scientists would have good reason to feel discouraged. Policy makers may pay strong lip service to their warnings, but they take modest actions. Advances in the science have also disappointed: Scientists' findings have gained little precision in decades, and strong variation and disagreement remains across the assessments of different climate models and among experts. Fortunately, the uncertainty that blights predictions of climate change and its impacts is likely to be reduced in some key areas. As long as scientific research continues, some of Nature's secrets will inevitably be revealed. Yet, what would be the value of such an advance in the science if policy makers do not respond? This article responds to this question and provides a different and supplementary justification for a vigorous climate science research effort: better predictions on the consequences of climate change will lead to better decisions on adaptation.

The basic intuition behind this result is as follows. If future climate change will be severe, GDP will be significantly impaired and major capital losses will be incurred. If climate change is only moderate, the losses will be much less. The welfare that we can expect when confronted by such uncertainty depends on the information we have about the likelihood of severe and moderate climate change, and how we use this information in making our adaptation decisions. Our welfare will therefore also depend on how flexible our adaptation strategies are. The adaptation strategies we address are saving for an impaired tomorrow and physical adaptation measures, such as building seawalls or locating facilities in less desirable but less vulnerable locations.

Better predictions on the probabilities of severe and moderate consequences will improve adaptation decisions and thus raise welfare. Even when we are in a constrained world in which the only adaptation decision concerns saving for an uncertain future. Better predictions will raise expected welfare by reducing the need for precautionary savings, and allowing more effective consumption smoothing. When physical adaptation measures are also available, the prospect of improved signals is valued even higher. In essence, a better signal allows us to find the correct balance between 
damage limitation investments and precautionary saving and tailor the adaptation to the effects of climate change in different future states of the world.

Given the renewed prominence of adaptation in the high-level negotiations on climate change, this is at the very least a morale boosting result for climate scientists. The results show there is good reason to provide more refined scientific information about climate change at the level of those who inevitably must adapt.

\section{References}

[1] IPCC 2014. Summary for policymakers. In Climate Change 2014: Impacts, Adaptation, and Vulnerability. Part A: Global and Sectoral Aspects. Contribution of Working Group II to the Fifth Assessment Report of the Intergovernmental Panel on Climate Change [Field CB, Barros VR, Dokken DJ, Mach KJ Mastrandrea MD, Bilir TE, Chatterjee M, Ebi KL, Estrada YO, Genova RC, Girma B, Kissel ES, Levy AN, MacCracken S, Mastrandrea PR, and White LL (eds.)]. Cambridge University Press, Cambridge, United Kingdom and NewYork, NY, USA, pp. 1-32.

[2] IPCC 2013 Intergovernmental Panel on Climate Change Fifth Assessment Report, Final Synthesis Report for Policy Makers. See http://www.ipcc.ch/index.htm.

[3] IPCC 2007 Intergovernmental Panel on Climate Change Fourth Assessment Report, Working Group I. http://www.ipcc.ch/index.htm.

[4] Copenhagen Accord (2009). FCCC/CP/2009/11/Add.1 See http:/unfccc.int/resource/docs/2009/cop15/eng/11a01.pdf.

[5] Barrett S, Environment and Statecraft: The Strategy of Environmental TreatyMaking, Oxford University Press, Oxford, 2003.

[6] Barrett S, The theory of international environmental agreements, in: Maler KG and Vincent J (Eds.), Handbook of Environmental Economics, vol. 3, Elsevier, Amsterdam, 2005, 1457-1516.

[7] Finus M 2001. Game Theory and International Environmental Cooperation, Edward Elgar, Cheltenham, UK.

[8] Wagner UJ 2001. The design of stable international environmental agreements: economic theory and political economy, textitJournal of Economic Surveys 15, $3,377-411$. 
[9] Barrett, S 2013. Climate treaties and approaching catastrophes, J Environ Econ Manage, http://dx.doi.org/10.1016/j.jeem.2012.12.004i

[10] Groom B, Gatti JRJ, Goeschl T and Swanson T 2012. Bargaining over Global Public Goods. Chapter 12 In: Global Environmental Commons: Analytical and Political Challenges in Building Governance Mechanisms, Edited by Brousseau E, Dedeurwaerdere T, Jouvet P-A and Willinger M, Oxford University Press, Oxford, UK.

[11] Wolfram C, Shelef O, and Gertler PJ 2012. How will energy demand develop in the developing world?. NBER working paper 17747. National Bureau of Economic Research.

[12] Kahn M 2014. Climate Change Adaptation: Lessons from Urban Economics. NBER Working Paper 20716, National Bureau of Economic Research http://www.nber.org/papers/w20716

[13] Schelling T 1995. Intergenerational Discounting. Energy Pol., 23, 4-5, 395-401.

[14] Roy D and Zeckhauser R 2015. Grappling with Ignorance: Frameworks from Decision Theory, Lessons from Literature. Journal of Benefit Cost Analysis, forthcoming.

[15] Millner A 2012. Climate prediction for adaptation: Who needs what?, Climatic Change, 110, 1-2, 143-167 http://dx.doi.org/10.1007/s10584-011-0073-1

[16] Dessai S, Hulme M, Lempert R and Pielke Jr R 2007. Climate prediction: a limit to adaptation? Ch 5 in Adapting to Climate Change: Thresholds, Values, Governance, eds. Adger WN, Lorenzoni I and Oï $\frac{1}{2}$ Brien KL. Cambridge University Press, Cambridge.

[17] Seo NJ and Mendelsohn R 2012. An analysis of crop choice: Adapting to climate change in South American farms, Ecol. Econ. 67, 109-116.

[18] Epstein LG 1980. Decision Making and the Temporal Resolution of Uncertainty, Int. Econ. Rev., 21, 2, 269-83.

[19] Gollier C, Jullien B and Treich N 2000. Scientific progress and irreversibility: an economic interpretation of the Precautionary Principle. J. Pub. Econ., 75, 229-253. w 
[20] Kelly DL and Kolstad CD 1999. Bayesian learning, growth, and pollution, J. Econ. Dyn. Contr. 23 4, 491-518.

[21] Millner A, Dietz S, Heal G (2013) Scientific ambiguity and climate policy. Environ Resource Econ 55: 21-46.

[22] Hall JW, Fu G and Lawry J 2007. Imprecise probabilities of climate change: aggregation of fuzzy scenarios and model uncertainties, Climatic Change 81, $3-4,265-281$

[23] Weitzman ML 2010. What Is The Damages Function For Global Warming And What Difference Might It Make?. Climate Change Economics 1, 1, 57-69.

[24] Pindyck RS 2013. The Climate Policy Dilemma. Rev Environ Econ Policy 7, 2, $219-237$.

[25] Nordhaus W 2008. A question of balance. Princeton Press.

[26] Freeman MC, Wagner G and Zeckhauser R 2015. Uncertainty, Scientific advances on Climate Change, and Consumption Decisions, Phil. Trans. Roy. Soc. $A$ This edition of the journal.

[27] Roe GH and Baker MB 2007. Why Is Climate Sensitivity So Unpredictable? Science, $\mathbf{3 1 8}$ pp 629-33.

[28] Wagner G and Weitzman ML 2015. Climate Shock: the Economic Consequences of a Hotter Planet. Princeton University Press.

[29] Millner A, 2011. Do Probabilistic expert elicitations capture scientists' uncertainty about climate change?, Climatic Change, 116, 427-436, doi.10.1007/s10584-012-0620-4

[30] Zickfeld K, Morgan MG, Frame DJ, Keith DW (2010) Expert judgments about transient climate response to alternative future trajectories of radiative forcing. Proc. Natl. Acad. Sci. 107, 28, 12451-12456. doi:10.1073/pnas.0908906107

[31] Botzen WJW, Aerts, JCJH and van den Bergh JCJM 2009. Willingness of homeowners to mitigate climate risk through insurance. Ecol. Econ., 68 8-9, $2265-2277$.

[32] Huppert HE and Sparks RSJ 2006. Extreme natural hazards: population growth, globalization and environmental change. Phil. Trans. R. Soc. A 364, 1875-1888, doi:10.1098/rsta.2006.1803. 
[33] Pielke Jr RA, Sarewitz D and Byerly Jr R 2000. Decision making and the future of nature: understanding and using predictions, in Prediction: Science, Decision Making and the Future of Nature Sarewitz D, Pielke Jr RA and Byerly Jr , R (eds.). Washington, DC : Island Press, 361-387.

[34] Pielke Jr R, Prins G, Rayner S and Sareqitz D 2007. Lifting the taboo on adaptation. Nature, 445, 8 .

[35] Stern N 2007. The Stern Review of the Economics of Climate Change, Cambridge University Press, Cambridge, UK.

[36] Adger NW, Paavola J, Huq S and Mace MJ 2008. Fairness in adaptation to climate change. MIT Press, Cambridge, Massachusetts.

[37] Huq S, Rahman A, Konate M, Sokona Y and Reid H 2004. Mainstreaming adaptation to climate change in Least Developed Countries (LDCs). Clim. Pol., 4, 1, 25-43.

[38] CAF 2007. The Cancun Adaptation Framework, http://unfccc.int/resource/ docs/2010/cop16/eng/07a01.pdf

[39] Fankhauser S, Smith J, Tol R 1999. Weathering climate change: some simple rules to guide adaptation decisions, Ecol. Econ. 30, 67-78.

[40] Konrad, KA and Thum MP 2012. The Role of Economic Policy in Climate Change Adaptation. Working Paper of the Max Planck Institute for Tax Law and Public Finance No. 2012-08,http://ssrn.com/abstract $=2158578$

[41] Gorst A, Groom B and Dehlavi A 2015. Crop Productivity and Adaptation to Climate Change in Pakistan. Grantham Research Institute on Climate Change and the Environment Working paper No. 189.

[42] Di Falco S, Veronesi M and Yesuf M 2011. Does Adaptation to Climate Change Provide Food Security? Micro Evidence from Ethiopia. Amer. J. Ag. Econ. 93 $3,829-846$.

[43] Dell M, Jones BF and Olken BA 2014. What Do We Learn from the Weather? The New Climate-Economy Literature. J. Econ. Lit., 52, 3, 740-98.

[44] Kahn M 2005. The Death Toll from Natural Disasters: The Role of Income, Geography, and Institutions. Rev. Econ. Stat., 87 2, 271-284. 
[45] Botzen, WJW and van den Bergh, JCJM 2012. Risk attitudes to low-probability climate change risks: WTP for flood insurance. J. Econ. Beh. and Org., 82, 1, $151-166$.

[46] Ridgwell A, Freeman C and Lampitt R (eds) 2012. Geoengineering: taking control of our planet's climate?, Phil. Trans. R. Soc. A 370, 1974,

[47] Kimball, Miles S 1990. Precautionary Saving in the Small and in the Large. Econometrica, 58 1, 53-73.

[48] Leland, Hayne E 1968. Saving and Uncertainty: The Precautionary Demand for Saving, Q J Econ, 82 3, 465-473.

[49] Pindyck, Robert S. 2012. Uncertain Outcomes and Climate Change Policy. $J$ Environ Econ Manage, 63 3, 289-303. (doi:10.1016/j.jeem.2011.12.001).

[50] Jawitz James W 2004. Moments of Truncated Continuous Univariate Distributions. Adv Water Resour, 27 3, 269-281 (doi:10.1016/j.advwatres.2003.12.002).

[51] Weitzman, Martin L. 2009. On Modeling and Interpreting the Economics of Catastrophic Climate Change. Rev Econ Stat, 91 1, 1-19. (doi:10.1162/rest.91.1.1).

[52] Pindyck, Robert S. 2013. The Climate Policy Dilemma. Rev Environ Econ Policy, 7 2, 219-237. (doi: 10.1093/reep/ret007).

[53] Berkhout F, Gouldson AP 2003. Shaping, Modulating, Adapting: Perspectives on technology, environment and policy, In: Berkhout F, Leach, M and Scoones I (Eds) Negotiating Environmental Change: Advances in environmental social science, Edward Elgar.

[54] Marshak, Jacob 1971. Economics of Information Systems, J Am Stat Assoc, 66 $333,192-219$.

[55] Hirshleifer J, John G. Riley 1979. The Analytics of Uncertainty and Information - An Expository Survey. J Econ Lit, 17 4, 1375-1421.

\section{Appendix}

In this appendix we prove Results 1 and 2 . 


\subsection{Result 1}

If we receive the full signal at $t=1$, then future endowment is fully known. In this case, given that the utility function is concave, it is optimal to perfectly smooth consumption across time: $c_{t}=\left(e_{1}+e_{2}\right) / 2$ for $t=1,2$. Therefore the expected welfare at time $t=1-\delta$ is:

$$
E_{1-\delta}[\Psi]=E_{1-\delta}\left[2 U\left(\frac{e_{1}+e_{2}}{2}\right)\right] .
$$

With no signal, $E_{1-\delta}[\Psi]=\Psi$, since there is no new information. Expectations are the same whether taken at time $t=1-\delta$ or $t=1$. Therefore:

$$
E_{1-\delta}[\Psi]=\max _{c_{1}} U\left(c_{1}\right)+E_{1-\delta} U\left(e_{2}+e_{1}-c_{1}\right)
$$

Undertaking the optimisation gives:

$$
U^{\prime}\left(c_{1}^{*}\right)=E_{1-\delta} U^{\prime}\left(e_{2}+e_{1}-c_{1}^{*}\right)
$$

where $c_{1}^{*}$ denotes the optimal consumption level. By Jensen's inequality

$$
E_{1-\delta} U^{\prime}\left(e_{2}+e_{1}-c_{1}^{*}\right) \geq U^{\prime}\left(E_{1-\delta}\left[e_{2}+e_{1}\right]-c_{1}^{*}\right) \quad U^{\prime \prime \prime}(\cdot) \geq 0,
$$

where the inequality is strict if and only if $U^{\prime \prime \prime}(\cdot)=0$. Then

$$
U^{\prime}\left(c_{1}^{*}\right) \geq U^{\prime}\left(E_{1-\delta}\left[e_{2}+e_{1}\right]-c_{1}^{*}\right) \quad U^{\prime \prime \prime}(\cdot) \geq 0 .
$$

Now notice that if

$$
c_{1}^{*}=E_{1-\delta}\left[\frac{e_{2}+e_{1}}{2}\right],
$$

then the left- and right-hand sides of equation (2) are equal. This is the expected level of time 1 consumption under a full signal. When equation (2) is an inequality, $c_{1}^{*}$ must be less than the right hand side of equation $(3)$ because $U^{\prime \prime}(\cdot)<0$. This proves Result 1.2 .

To establish Result 1.1, note that $c_{1}^{*}$ cannot be equal to both $\left(e_{1}+l\right) / 2$ and $\left(e_{1}+h\right) / 2$, the optimal consumption levels at time $t=1$ following the receipt of a bad and good signal respectively. Since consumption decisions under no signal do not optimise expected welfare in the presence of a signal, the result follows immediately. This is also a special case of Result A2.4 below. 


\section{$7.2 \quad$ Result 2}

We prove four sub-results. From them Result 2 in the body of the text follows immediately

Result A2. If we receive a partial signal in the interval $[1-\delta, 1]$, then:

A2.1 Let $\sigma_{1}^{2}$ denote the volatility of time 2 endowment, $e_{2}$, as calculated at time 1 . Let $\sigma_{1}^{2}=\sigma_{G}^{2}$ if the signal received is good and $\sigma_{1}^{2}=\sigma_{B}^{2}$ if the signal received is bad. Then $\sigma_{G}^{2}<\sigma^{2}$ if $\varepsilon_{G}>1-2 p$ and $\sigma_{B}^{2}<\sigma^{2}$ if $\varepsilon_{B}>2 p-1$, where $\sigma^{2}$ is the volatility of time 2 endowment calculated at time $1-\delta$. In addition, the expectation of $\sigma_{1}^{2}$ as calculated at time $1-\delta, \pi \sigma_{G}^{2}+(1-\pi) \sigma_{B}^{2}$, is monotonic decreasing in the strength of the signal, $\varepsilon_{G}$.

A2.2 If prudence is zero, then the expectation at time $t=1-\delta$ of time 1 consumption, $E_{1-\delta}\left[c_{1}\right]$, is unaffected by the anticipation of any signal.

A2.3 If prudence is positive, then the stronger the signal that we will receive (the greater is $\varepsilon_{G}$ ), the higher is our expectation of time 1 consumption, $E_{1-\delta}\left[c_{1}\right]$.

A2.4 For all monotonic increasing and concave utility functions, the stronger the signal that we will receive, the larger is the expected welfare as calculated at time $t=1-\delta ; E_{1-\delta}[\Psi]$

Proof. Use the notation $\mu=p h+(1-p) l$ and $\sigma^{2}=p(h-\mu)^{2}+(1-p)(l-\mu)^{2}$ to denote the mean and variance of time 2 endowment conditional on the information available at $t=1-\delta$. It is straightforward to verify that $\sigma^{2}=p(1-p)(h-l)^{2}$. Similarly, let $\mu_{G}=\left(p+\varepsilon_{G}\right) h+\left(1-p-\varepsilon_{G}\right) l, \mu_{B}=\left(p-\varepsilon_{B}\right) h+\left(1-p+\varepsilon_{B}\right) l$, $\sigma_{G}^{2}=\left(p+\varepsilon_{G}\right)\left(h-\mu_{G}\right)^{2}+\left(1-p-\varepsilon_{G}\right)\left(l-\mu_{G}\right)^{2}$, and $\sigma_{B}^{2}=\left(p-\varepsilon_{B}\right)\left(h-\mu_{B}\right)^{2}+$ $\left(1-p+\varepsilon_{B}\right)\left(l-\mu_{B}\right)^{2}$ denote the means and variances of time 2 endowment conditional on receiving the good $(G)$ and bad $(B)$ signal in the interval $[1-\delta, 1]$. It is again straightforward to verify that, for $\theta_{G}=\varepsilon_{G}(h-l)$ and $\theta_{B}=\varepsilon_{B}(h-l)$ :

$$
\begin{aligned}
\mu_{G} & =\mu+\theta_{G} \\
\mu_{B} & =\mu-\theta_{B} \\
\sigma_{G}^{2} & =\sigma^{2}+\varepsilon_{G}\left(1-2 p-\varepsilon_{G}\right)(h-l)^{2} \\
\sigma_{B}^{2} & =\sigma^{2}-\varepsilon_{B}\left(1-2 p+\varepsilon_{B}\right)(h-l)^{2} .
\end{aligned}
$$

$\sigma_{G}^{2}<\sigma^{2}$ if and only if $1-2 p-\varepsilon_{G}<0$. For $\sigma_{B}^{2}<\sigma^{2}, 1-2 p+\varepsilon_{B}>0$. It is also straightforward to verify that:

$$
\pi \sigma_{G}^{2}+(1-\pi) \sigma_{B}^{2}=\sigma^{2}-\frac{\pi}{1-\pi} \varepsilon_{G}^{2}(h-l)^{2}
$$


which decreases as $\varepsilon_{G}$ increases. This proves Result A2.1.

Now consider the welfare function at time 1 conditional on receiving the good signal, $\Psi_{G}$. Again, $E_{G}[\cdot]$ denotes the expectation taken at time $t=1$ conditional on the good signal.

$$
\Psi_{G}=\max _{c_{1}} U\left(c_{1}\right)+E_{G}\left[U\left(e_{1}+e_{2}-c_{1}\right)\right] .
$$

Define the variable $v$ as follows. Let $e_{2}=\mu_{G}+v=\mu+\theta_{G}+v$ for $v=h-\theta_{G}-\mu$ or $v=l-\theta_{G}-\mu$ depending on which state of the world occurs at $t=2$. Undertaking the optimisation and using $c_{1 G}^{*}$ to denote optimal consumption at time 1 conditional on receiving the good signal:

$$
U^{\prime}\left(c_{1 G}^{*}\right)=E_{G}\left[U^{\prime}\left(e_{1}+\mu+\theta_{G}+v-c_{1 G}^{*}\right)\right] .
$$

First consider the case when $U^{\prime \prime \prime}(\cdot)=0$. Then, by Jensen's inequality:

$$
U^{\prime}\left(c_{1 G}^{*}\right)=U^{\prime}\left(e_{1}+\mu+\theta_{G}-c_{1 G}^{*}\right),
$$

showing immediately that $c_{1 G}^{*}=\left(e_{1}+\mu+\theta_{G}\right) / 2$. By an analogous argument, if we receive the bad signal, $c_{1 B}^{*}=\left(e_{1}+\mu-\theta_{B}\right) / 2$. This results in

$$
\begin{aligned}
E_{1-\delta}\left[c_{1}\right] & =\pi c_{1 G}^{*}+(1-\pi) c_{1 B}^{*} \\
& =\frac{e_{1}+\mu}{2}+\frac{\pi \theta_{G}-(1-\pi) \theta_{B}}{2} \\
& =\frac{e_{1}+\mu}{2}+\frac{\pi \varepsilon_{G}-(1-\pi) \varepsilon_{B}}{2}(h-l),
\end{aligned}
$$

and, through the relation between $\varepsilon_{G}$ and $\varepsilon_{B}$, this is equal to $\left(e_{1}+\mu\right) / 2$ for any potential signal that we might receive. This proves Result A2.2.

With $U^{\prime \prime \prime}(\cdot)>0$, we can view $U^{\prime}(\cdot)$ as a pseudo-utility function that is monotonic decreasing and convex. Again, suppose that we have received the good signal at $t=1$. Note that $\operatorname{Var}(v)=\sigma_{G}^{2}$ and, as usual, $c_{2 G}=e_{1}+e_{2}-c_{1 G}=e_{1}+\mu+\theta_{G}+v-c_{1 G}$. Using a standard Pratt-Arrow approach, we can replace this stochastic consumption with the expected consumption level $e_{1}+\mu+\theta_{G}-c_{1 G}$ minus a prudence adjustment $\psi_{G}$ :

$$
\begin{aligned}
E_{G}\left[U^{\prime}\left(e_{1}+\mu+\theta_{G}+v-c_{1 G}\right)\right] & =U^{\prime}\left(e_{1}+\mu+\theta_{G}-c_{1 G}-\psi_{G}\right) \\
\psi_{G} & \approx-\frac{1}{2} \sigma_{G}^{2} \frac{U^{\prime \prime \prime}\left(e_{1}+\mu+\theta_{G}-c_{1 G}\right)}{U^{\prime \prime}\left(e_{1}+\mu+\theta_{G}-c_{1 G}\right)} \\
& =\frac{1}{2} \sigma_{G}^{2} P_{G},
\end{aligned}
$$


where $P_{G}=-U^{\prime \prime \prime}\left(e_{1}+\mu+\theta_{G}-c_{1 G}\right) / U^{\prime \prime}\left(e_{1}+\mu+\theta_{G}-c_{1 G}\right)$ is the prudence of consumption at time 2 in the good state if endowment equals the expected value at this time conditional on the signal received at $t=1$.

Given this, from equation 4 :

$$
c_{1 G}^{*}=\frac{e_{1}+\mu+\theta_{G}-\psi_{G}}{2} .
$$

Similarly,

$$
\begin{aligned}
c_{1 B}^{*} & =\frac{e_{1}+\mu-\theta_{B}-\psi_{B}}{2} \\
\psi_{B} & =\frac{1}{2} \sigma_{B}^{2} P_{B} .
\end{aligned}
$$

Therefore, under the assumption that prudence is approximately constant at value $P$ over the range of interest:

$$
\begin{aligned}
E_{1-\delta}\left[c_{1}\right] & =\pi c_{1 G}^{*}+(1-\pi) c_{1 B}^{*} \\
& =\frac{e_{1}+\mu}{2}+\frac{\pi \varepsilon_{G}-(1-\pi) \varepsilon_{B}}{2}(h-l)-\frac{\pi \sigma_{G}^{2}+(1-\pi) \sigma_{B}^{2}}{4} P \\
& =\frac{e_{1}+\mu}{2}-\left(\sigma^{2}-\frac{\pi}{1-\pi} \varepsilon_{G}^{2}(h-l)^{2}\right) \frac{P}{4} .
\end{aligned}
$$

The final term gets less negative the stronger is the signal $\varepsilon_{G}$. A more powerful signal increases expected time 1 consumption provided the agent is prudent. This proves Result A2.3.

Result A2.4 follows immediately from, for example, [54] and [55]. A less clear signal can be treated as a "garbled" interpretation of a stronger signal. As an example, consider a world where unconditionally the moderate and severe outcomes at $t=2$ are equally likely. Assume that, if we receive the stronger good (bad) signal at $t=1$, then the probability of having the moderate outcome is revised to $70 \%(30 \%)$. A good (bad) weaker signal instead revises these probabilities to $60 \%$ $(40 \%)$.

The weak signal can be imaged as a world where we receive the strong signal, but where it may be misread or "garbled". In the example, imagine that there is a $25 \%$ chance that we will mis-read a true good (bad) strong signal as being bad (good) instead. Then on receiving a truly good strong signal, there is a $75 \%$ probability that this will be interpreted correctly as a good strong signal and a $25 \%$ that it will be mistakenly read as a bad strong signal. The estimated probability of the moderate state occurring at time 2 is $75 \% * 70 \%+25 \% * 30 \%=60 \%$ conditional on receiving 
this garbled signal. Similarly, on receipt of a bad signal, the estimated probability of the moderate state occurring at time 2 is $75 \% * 30 \%+25 \% * 70 \%=40 \%$. The probabilities are identical to those we assign under the weaker signal in the absence of garbling. As the probabilities of the stronger signal bracket the probabilities of the weaker signal, it is generally true that weaker signals can be interpreted as garbled stronger signals.

Under these conditions, as argued by [55] (p. 1397), the stronger signal "must lead to higher utility so long as there is any change in best conditional action under either message". As shown above, optimal consumption levels at $t=1$ depend on the value of $\varepsilon_{G}$, so conditional action does depend on the strength of the message. This completes the proof of Result A2.4 


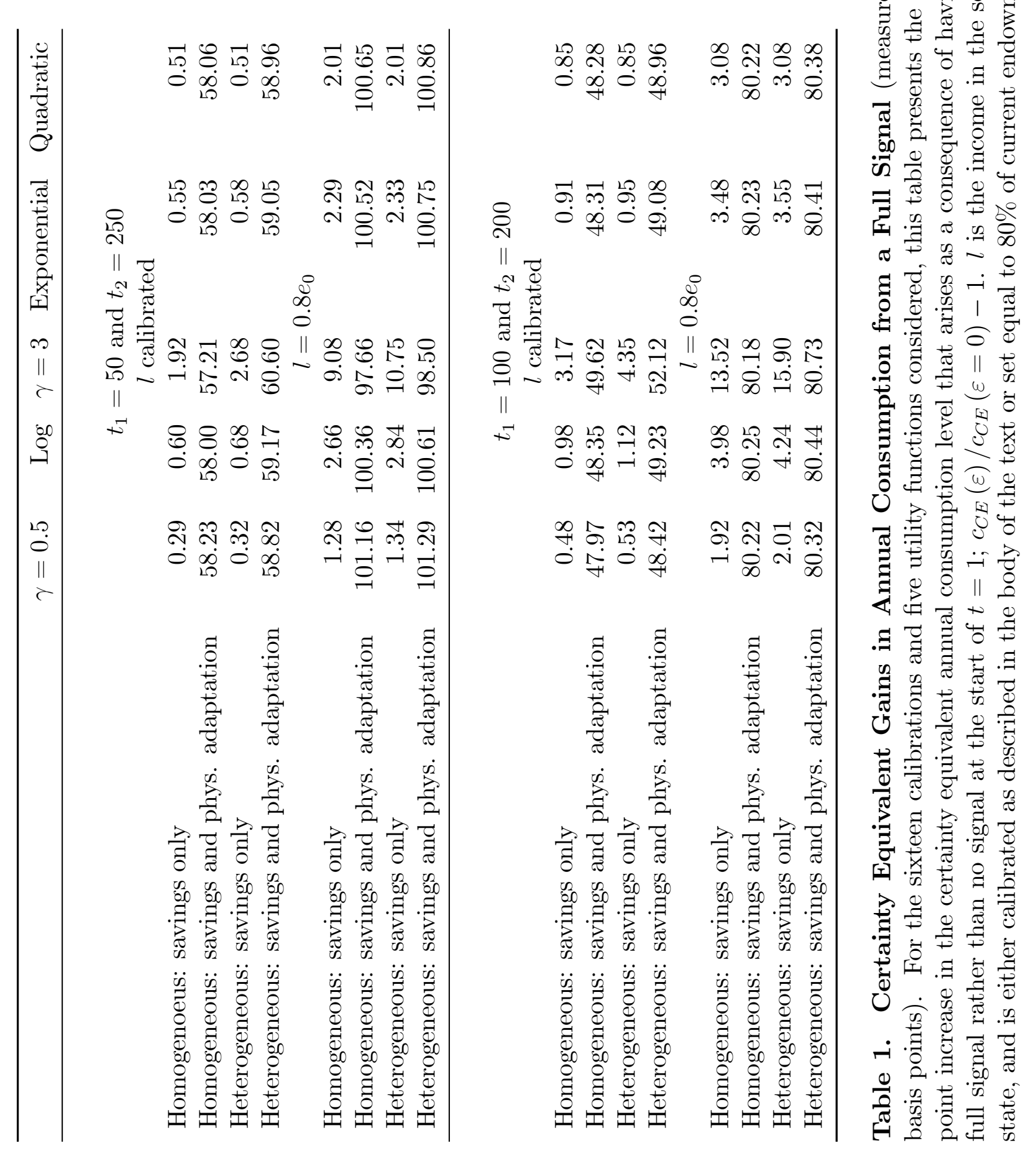




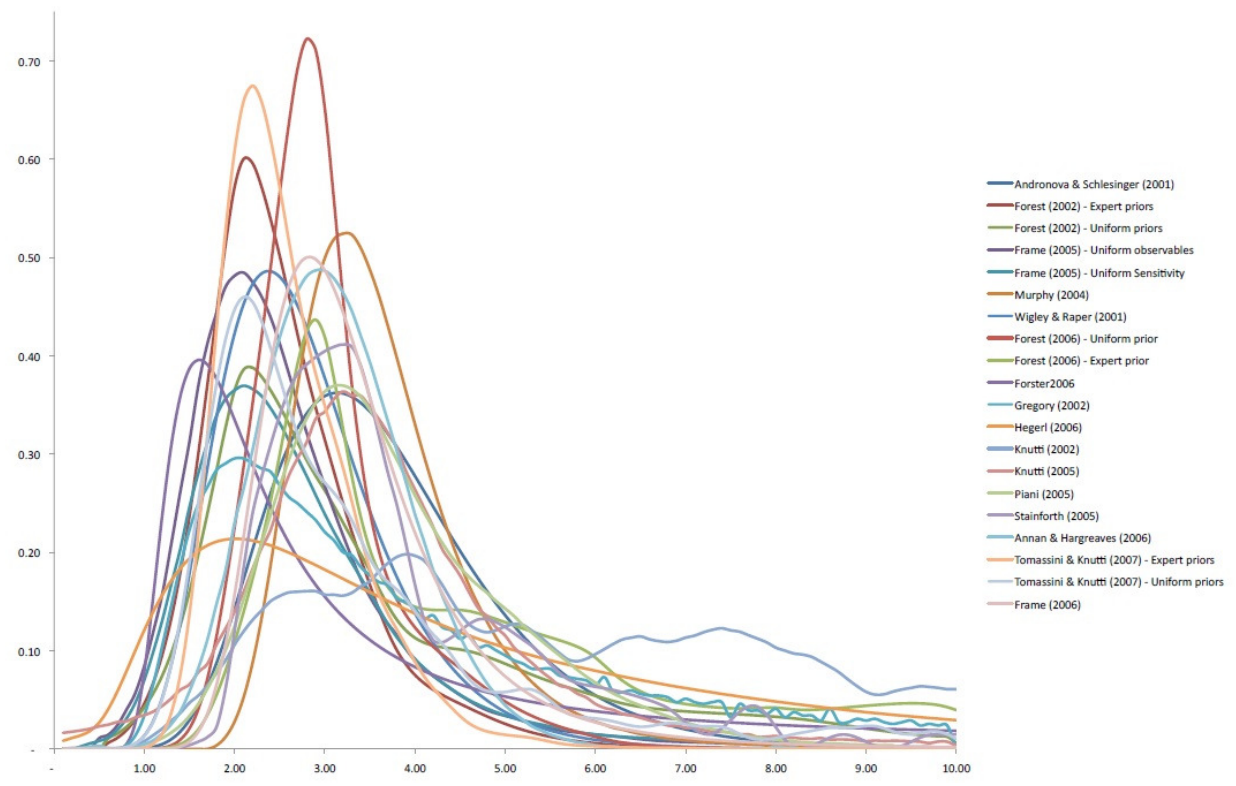

Figure 1: Estimates of Climate Sensitivity Probability Densities [21]

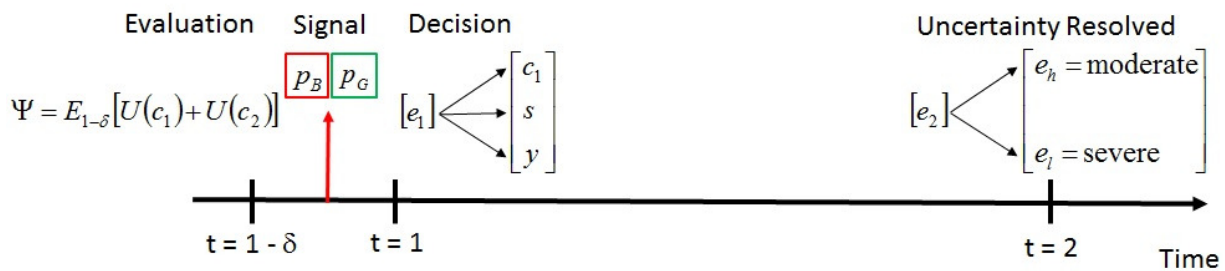

Figure 2: Timeline for valuation, decision and realisation of uncertainty 


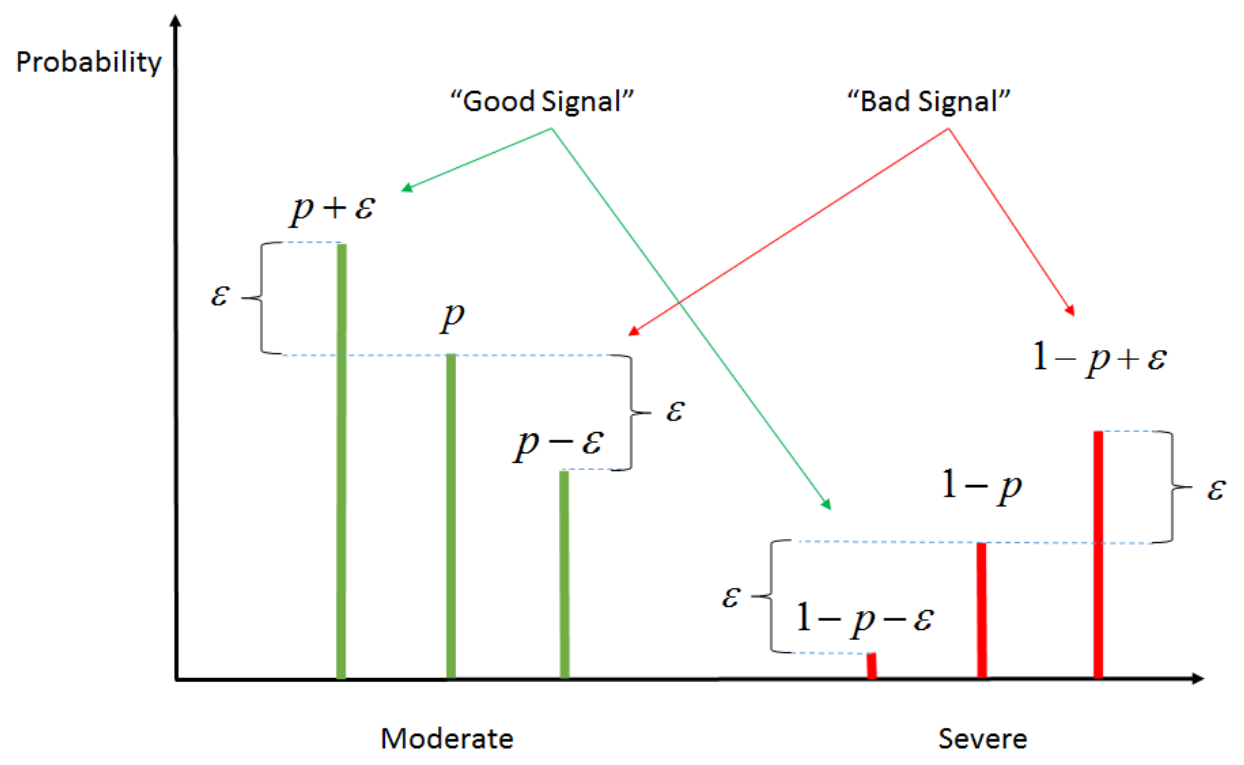

Figure 3: Illustration of 'Good' signals and 'Bad' signals 

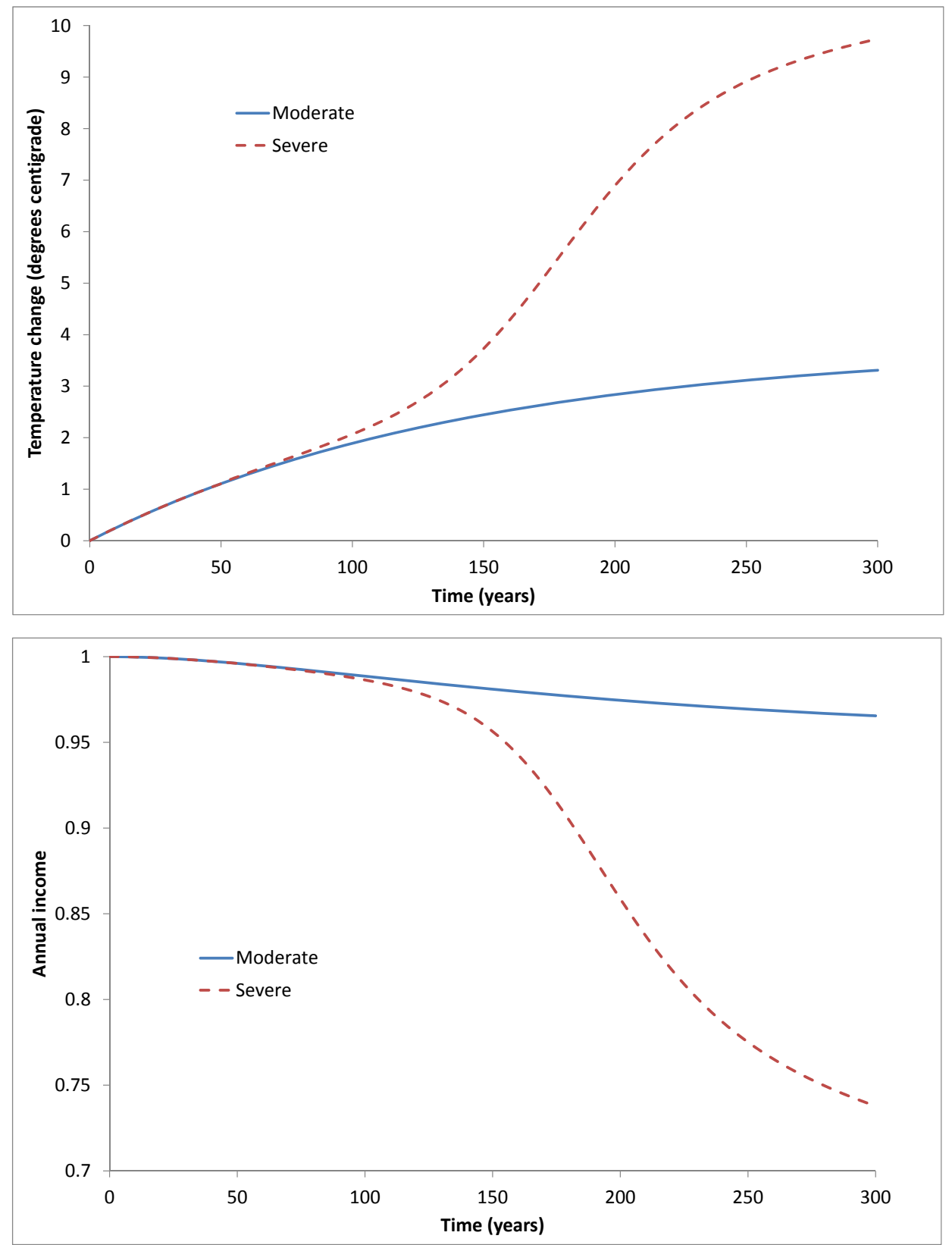

Figure 4. The Evolution of Temperature Change and Annual Income Under the Moderate and Severe Scenarios. 


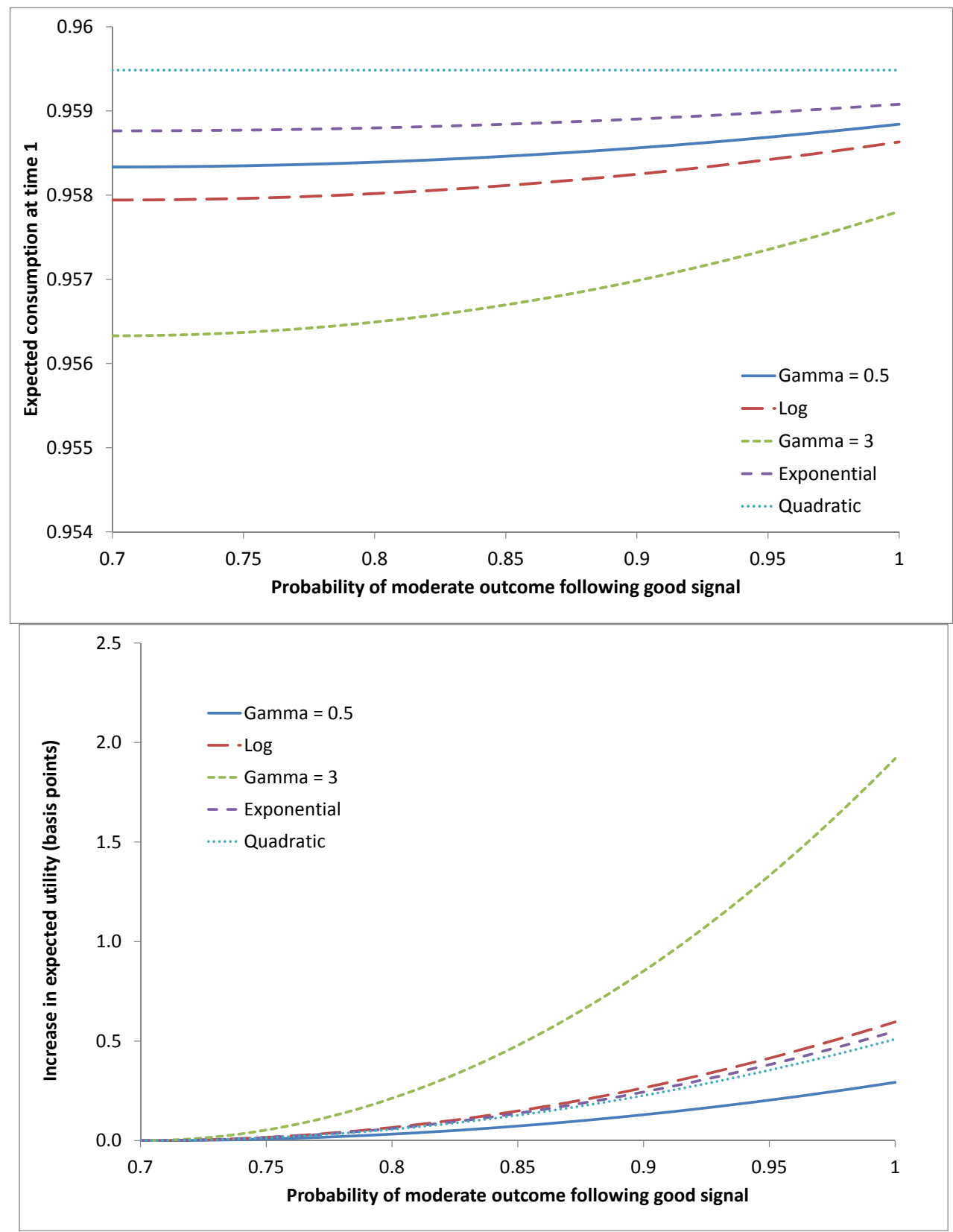

Figure 5. Gains in Consumption and Expected Utility as Signal Strength Increases. This shows the expectation, as calculated at $t=1-\delta$, of $t=1$ consumption and expected future welfare expressed as a basis point $\left(1 / 100^{\text {th }} \%\right)$ increase in the certainty equivalent consumption level (compared to the no signal case) as the strength of a partial signal changes. Endowment over the first $t_{1}$ years must be either consumed or saved in a risk-free asset with a zero interest rate. 

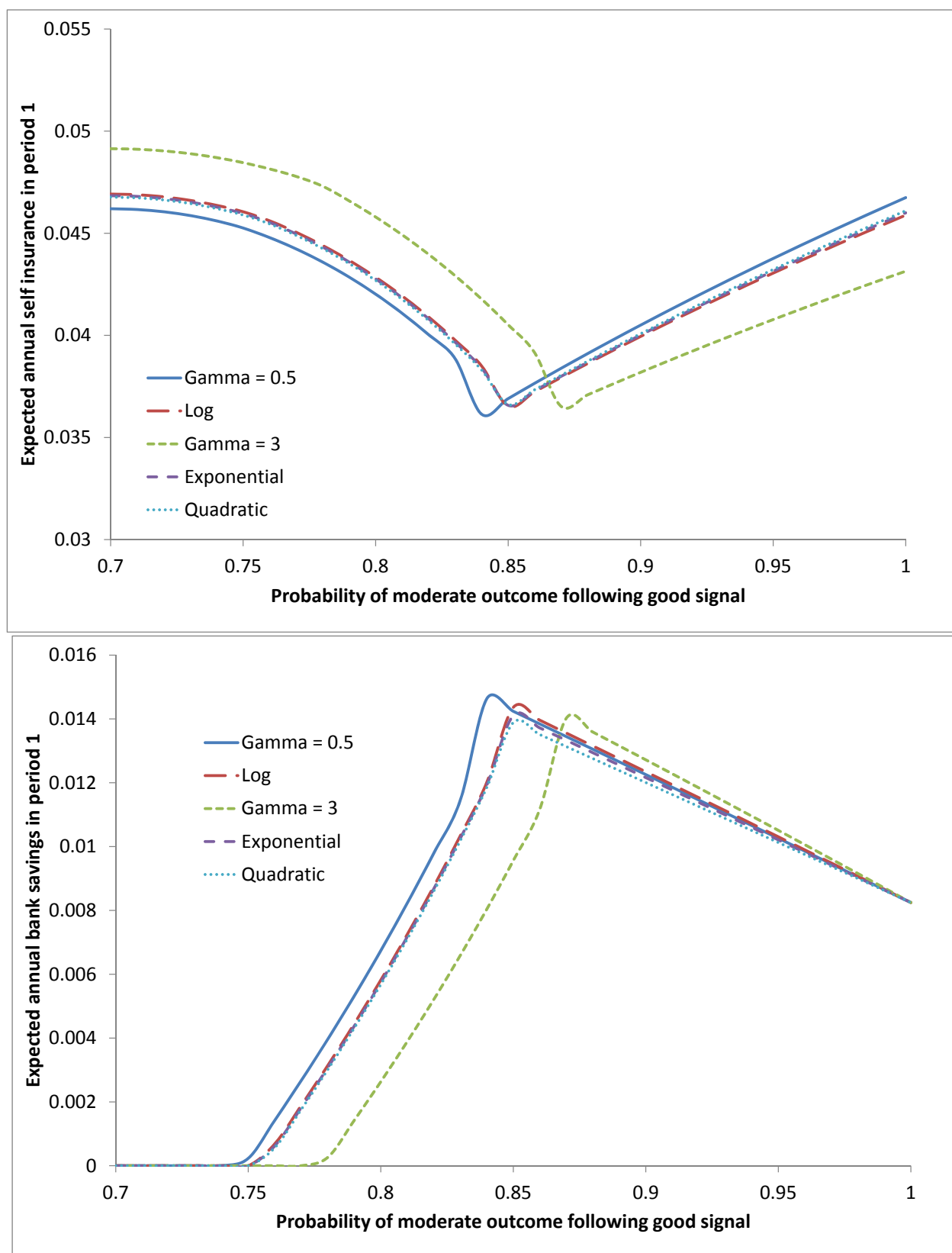

Figure 6. Investment in Physical Adaptation and Savings as Signal Strength Increases. This shows the expectation, as calculated at $t=1-\delta$, of the levels of investment in the self insurance policy and the risk-free savings opportunity. Endowment at $t=1$ can be either consumed, saved in a risk-free asset with a zero interest rate, or invested in a physical adaptation project that partially protects against the severe outcome. 

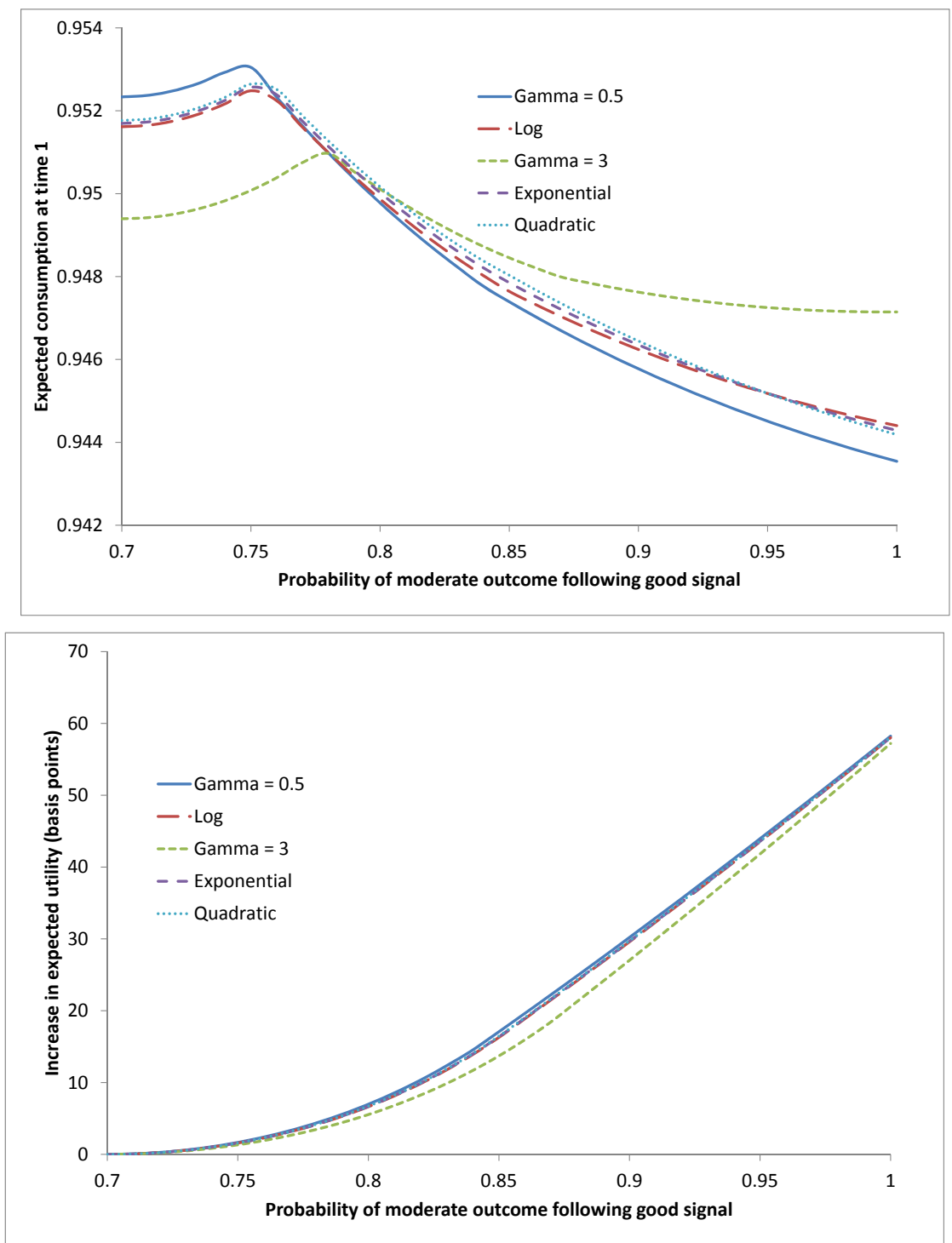

Figure 7. Gains in Consumption and Expected Utility with Physical Adaptation as Signal Strength Increases. Following Figure 3, this shows the expectation, as calculated at $t=1-\delta$, of $t=1$ consumption and expected future welfare expressed as a basis point $\left(1 / 100^{t h} \%\right)$ increase in the certainty equivalent consumption level (compared to the no signal case) as the strength of a partial signal changes. Endowment at $t=1$ can be either consumed, saved in a risk-free asset with a zero interest rate, or invested in a physical adaptation measure that partially protects against the severe outcome. 